\title{
In silico results of $\chi$-Opioid receptor antagonists as ligands for the second bromodomain of the Pleckstrin Homology Domain Interacting Protein
}

\author{
Lemmer R. P. EL ASSAL (lelassal@hushmail.com)
}

$25 / 08 / 2018$

\begin{abstract}
Pleckstrin Homology Domain Interacting Protein (PHIP) is a member of the BRWD1-3 Family (Bromodomain and WD repeat-containing proteins). PHIP (BRWD2, WDR11) contains a WD40 repeat (methyl-lysine binder) and 2 bromodomains (acetyl-lysine binder). It was discovered through interactions with the pleckstrin homology domain of Insulin Receptor Signalling (IRS) proteins and has been shown to mediate transcriptional responses in pancreatic islet cells and postnatal growth. An initial hit for the second bromodomain of PHIP (PHIP(2)) was discovered in 2012, with consecutive research yielding a candidate with a binding affinity of $68 \mu \mathrm{M}$. PHIP(2) is an atypical category III bromodomain with a threonine (THR1396) where an asparagine residue would usually be. In the standard case, this pocket holds four water molecules, but in the case of PHIP(2), there is room for one extra water molecule - also known as "PHIP water", able to mediate interaction between THR1396 and the typical water network at the back of the binding pocket. We present first ever results of two $x$-Opioid receptor (KOR) antagonists with distinct pharmacophores having an estimated binding affinity in the $\mathrm{nM}$ to $\mu \mathrm{M}$ range, as well as higher binding affinities for every currently discovered PHIP(2) ligand towards KOR. Finally, we also demonstrate selectivity of LY-255582 and LY-2459989 towards PHIP(2) over other bromodomains.
\end{abstract}

\section{Introduction}

Pre-administration of methadone was shown to enhance the apoptotic effect of doxorubicin in leukemia cells with a proposed mechanism involving lowered cAMP concentrations by inhibition of adenylyl cyclase, leading to increased caspase activity. Likewise, significant reduction in apoptosis was demonstrated following an increase in intracellular cAMP concentration[1, $2,3]$ - it may however be possible that an increase in cAMP would simply mean an increase in CREBBP activity, a crucial transcriptional coactivator in the expression of P-Glycoprotein (P-GP) [4]. Furthermore, this hypothesis relies on the assumption that methadone is a P-GP inhibitor by itself, while it is only shown as a substrate[5, 6, 7], while other sources report significant reduction of methadone efflux with the specific by addition of P-GP inhibitors[8, 9, 10]. P-GP expression is directly regulated by attachment of a variety of transcriptional factors to the promoter region of the P-GP gene; examples thereof are: $\mathrm{p} 53[11], \mathrm{YB}-1[12]$ and NF- $\kappa \mathrm{B}[13]$.

Bromodomains are acetyl-lysine (KAc) reader regions involved in the modulation of gene expression.[14]They have now for a while been attractive targets for the treatment of diseases such as inflammation and cancer, bringing about the development of a range of chemical probes for the investigation of bromodomain (Brd) biology.[15] In 2010, JQ-1 and I-BET were reported as potent inhibitors of the bromo- and extra-terminal domain (BET) bromodomain,[16, 17]and later academic and industrial research has been targeting the BET bromodomains.[18, 19, 20, 21]

Pleckstrin Homology Domain Interacting Protein (PHIP) is a member of the BRWD1-3 Family (Bromodomain and WD repeat-containing proteins). PHIP (BRWD2, WDR11) contains a WD40 repeat (methyl-lysine binder) and 2 bromodomains 
(acetyl-lysine binder). It was discovered through interactions with the pleckstrin homology domain of Insulin Receptor Signalling (IRS) proteins and has been shown to mediate transcriptional responses in pancreatic islet cells and postnatal growth.

In addition to its role in IGF-signalling, it has been identified as the gene most highly overexpressed in metastatic melanomas, compared with primary tumors[22], activation of PHIP promotes melanoma metastasis, and can be used as a biomarker to classify a subset of primary melanomas[23], and that elevated PHIP copy number was associated with significantly reduced distant metastasis-free survival and disease-specific survival by Kaplan-Meier analyses and that PHIP plays an important role as a molecular marker of melanoma ulceration, metastasis and survival[24]. Furthermore, it was identified as an increased risk in breast cancer[25] and as a tumour suppressor in Group 3 medulobalstoma [26].

An initial hit for the second bromodomain of PHIP (PHIP(2)) was discovered in 2012 (PDB 3MB3[14]), with consecutive research yielding a candidate with a binding affinity of $68 \mu \mathrm{M}[27,28]$. $\mathrm{PHIP}(2)$ is an atypical category III bromodomain[14] with a threonine (THR1396) where an asparagine residue would usually be. In the standard case, this pocket holds four water molecules, but in the case of $\operatorname{PHIP}(2)$, there is room for one extra water molecule - also known as "PHIP water", able to mediate interaction between THR1396 and the typical water network at the back of the binding pocket.

Seeing how insulin can induce expression of P-GP[13], and PHIP is involved in insulin signaling, we decided to dock methadone against $\mathrm{PHIP}(2)$ to evaluate whether or not methadone in fact works by inhibiting interaction with KAc residues of histones by attaching to bromodomains - more specifically - PHIP(2). Upon estimating binding affinity in the micromolar region for methadone against PDB 5ENB[27] using HYDE [29, 30], a random set of opioids was chosen for screening. With more data, the search has shown a variety of $x$-Opioid receptor (KOR) antagonists having good estimated binding affinities against PHIP(2). Finally, two candidates with distinct pharmacophores were selected to probe against other bromodomains to show selectivity towards PHIP(2). Additionally, it was shown that every single molecule with high reported affinity towards PHIP(2) is estimated to have even higher affinity towards KOR.

\section{Results and discussion}

\section{Initial search}

\begin{tabular}{|c|c|c|c|c|}
\hline \multicolumn{1}{|c|}{ Ligand } & $\begin{array}{c}\text { HYDE } \\
\text { estimated } \\
\text { affinity } \\
\text { lower } \\
\text { bound }\end{array}$ & $\begin{array}{c}\text { HYDE } \\
\text { estimated } \\
\text { affinity } \\
\text { upper } \\
\text { bound }\end{array}$ & $\begin{array}{c}\mathrm{H}- \\
\text { bonds }\end{array}$ & \\
& $496 \mathrm{nM}$ & $49 \mu \mathrm{M}$ & 3 & $\mathrm{~K}_{\mathrm{i} \mu}=0.15 \mathrm{nM}, \mathrm{K}_{\mathrm{i} \delta}=90 \mathrm{nM}[31]$ \\
\hline \hline BDBM50033530 & $490.62 \mathrm{nM}[32]$ \\
\hline MCL-117 & $625 \mathrm{nM}$ & $62 \mu \mathrm{M}$ & 1 & $\mathrm{~K}_{\mathrm{i} \mu / \varkappa}=0.003 \mathrm{nM}, \mathrm{K}_{\mathrm{i} \delta}=0.62$ \\
\hline
\end{tabular}

The initial search was not very successful, yielding only two hits with nanomolar affinity. Even though MCL-117 shows no H-bonds towards the target, it was decided that the selectivity of both compounds towards $\mu$ and $x$ in comparison to $\delta$ warranted a restriction from including $\delta$-Opioid receptor ligands from further screening. 


\section{$\varkappa$-subtype agonists}

Table 2: Results for docking of KOR agonists

\begin{tabular}{|c|c|c|c|c|c|c|c|c|c|}
\hline Ligand & $\begin{array}{c}\text { HYDE } \\
\text { estimated } \\
\text { affinity } \\
\text { lower } \\
\text { bound }\end{array}$ & $\begin{array}{c}\text { HYDE } \\
\text { estimated } \\
\text { affinity } \\
\text { upper bound }\end{array}$ & $\begin{array}{c}\text { H- } \\
\text { bonds }\end{array}$ & $\begin{array}{c}\text { PRO } \\
1340\end{array}$ & $\begin{array}{l}\text { VAL } \\
1345\end{array}$ & $\begin{array}{c}\text { TYR } \\
1350\end{array}$ & $\begin{array}{c}\text { TYR } \\
1353\end{array}$ & $\begin{array}{l}\text { THR } \\
1396\end{array}$ & Notes \\
\hline \hline Cyclorphan & $6.9 \mu \mathrm{M}$ & $689 \mu \mathrm{M}$ & 1 & $\checkmark$ & $\checkmark$ & $\checkmark$ & $\sqrt{ }$ & $\mathrm{K}_{\mathrm{i} \varkappa}=0.03 \mathrm{nM}[33]$ \\
\hline Nalfurafine & $43 \mathrm{mM}$ & $>4 \mathrm{M}$ & 3 & $\checkmark$ & & $\checkmark$ & & $\sqrt{\mathrm{i} \varkappa}=0.025 \mathrm{nM}[34]$ \\
\hline
\end{tabular}

\section{Cyclorphan}
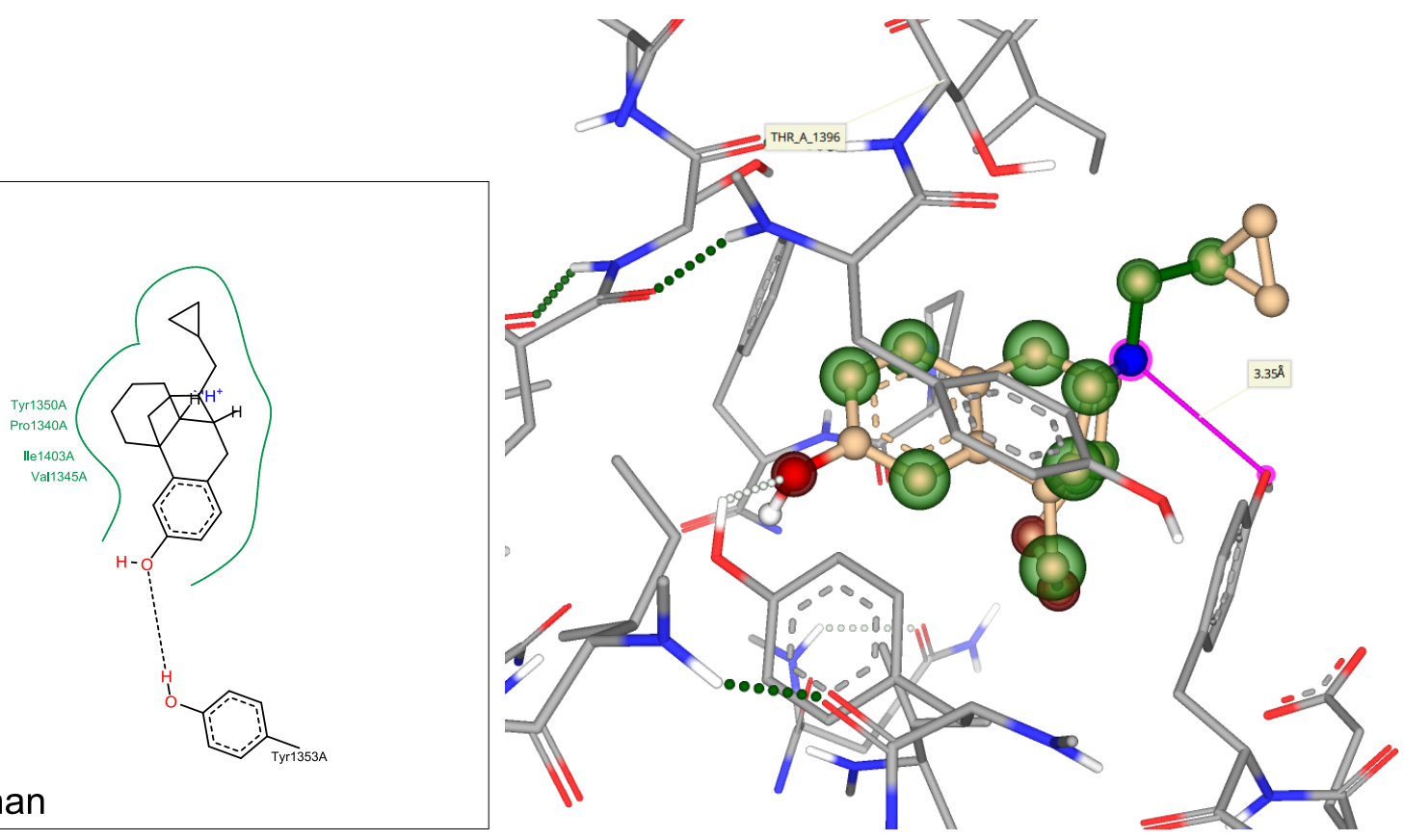

Figure 1: Three-dimensional docking view of Cyclorphan in SeeSAR 

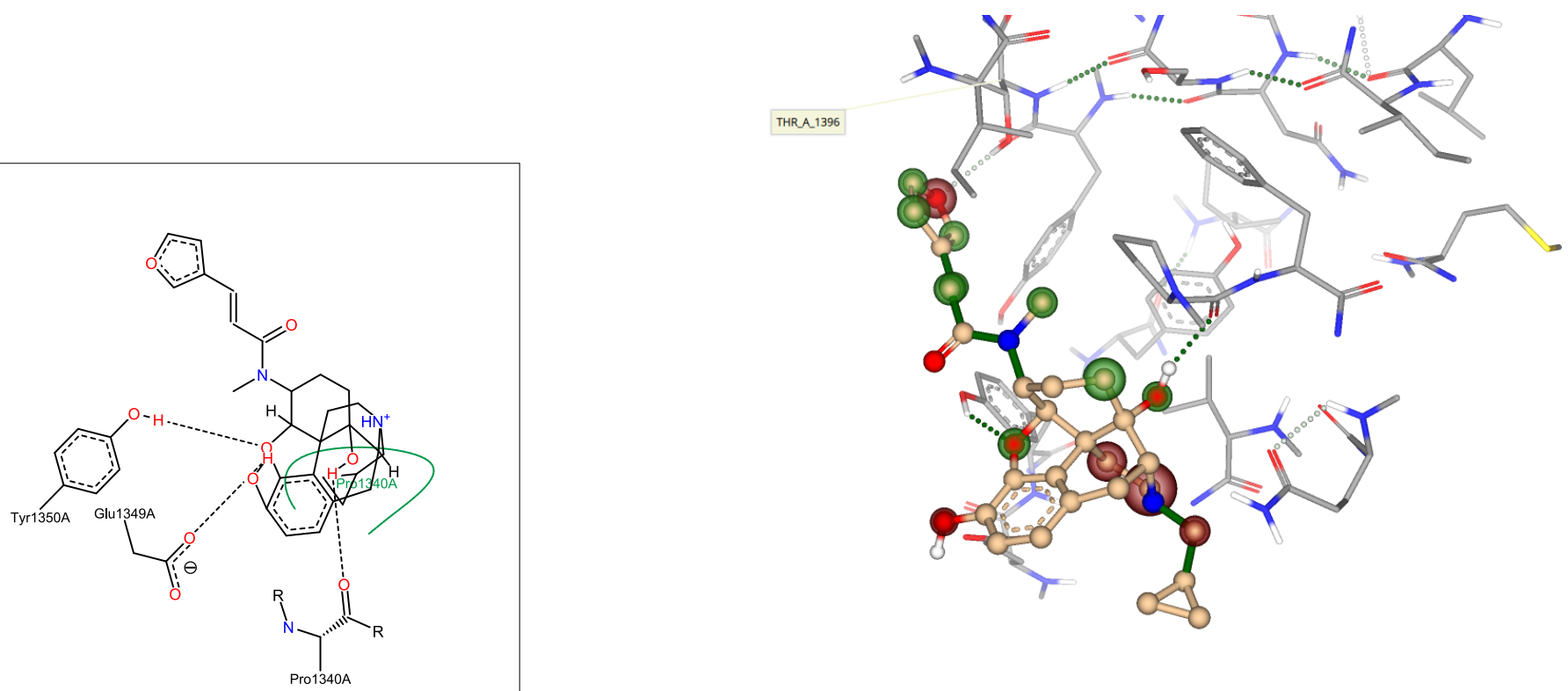

Nalfurafine

Figure 2: Three-dimensional docking view of Nalfurafine in SeeSAR

Even though the results are not that astonishing (since the estimated binding affinity range is not comparable with BDBM50033530), Cyclorphan has an estimated binding affinity that about ten-fold that of the experimental value of FMOOA463, although with only one recognized H-bond. A potentially additional residue could form an $\mathrm{H}$-bond with the nitrogen of the piperidine substructure: Tyr1350 (fig 1). This is unfortunately not confirmed because it is only recognized as hydrophobic interaction. In the case of Nalfurafine (fig 2), even though there is a predicted H-bond with THR1396, the estimated binding affinity range is in the $\mathrm{mM}$ region and the uncommon torsions make it unattractive for further investigation.

\section{$x$-subtype antagonists}

Since no ligand bearing green torsions with better binding affinity could be found over BDBM50033530, no definitive conclusion could be made and thus, the search continued on the $x$-subtype antagonists instead.

Table 3: Results for docking of KOR antagonists

\begin{tabular}{|c|c|c|c|c|c|c|c|c|l|}
\hline Ligand & $\begin{array}{c}\text { HYDE } \\
\text { estimated } \\
\text { affinity } \\
\text { lower } \\
\text { bound }\end{array}$ & $\begin{array}{c}\text { HYDE } \\
\text { estimated } \\
\text { affinity } \\
\text { upper } \\
\text { bound }\end{array}$ & $\begin{array}{c}\text { H- } \\
\text { bonds }\end{array}$ & $\begin{array}{c}\text { PRO } \\
1340\end{array}$ & $\begin{array}{c}\text { VAL } \\
1345\end{array}$ & $\begin{array}{c}\text { TYR } \\
1350\end{array}$ & $\begin{array}{l}\text { TYR } \\
1353\end{array}$ & $\begin{array}{l}\text { THR } \\
1396\end{array}$ & Notes \\
\hline \hline LY-255582 & $92 \mathrm{nM}$ & $9.1 \mu \mathrm{M}$ & 3 & $\checkmark$ & $\checkmark$ & & $\checkmark$ & & $\mathrm{K}_{\mathrm{i} \mu / \varkappa}=0.021 \mathrm{nM}[35]$ \\
\hline LY-2459989 & $1 \mu \mathrm{M}$ & $103 \mu \mathrm{M}$ & 2 & $\checkmark$ & & $\checkmark$ & & $\checkmark$ & $\mathrm{K}_{\mathrm{i} \varkappa}=0.18 \mathrm{nM}, \mathrm{K}_{\mathrm{i} \mu}=7.68 \mathrm{nM}[36]$ \\
\hline AT-076 & $11.8 \mu \mathrm{M}$ & $1.1 \mathrm{mM}$ & 4 & $\checkmark$ & $\checkmark$ & $\checkmark$ & & $\checkmark$ & $\mathrm{K}_{\mathrm{i} \varkappa}=1.14 \mathrm{nM}, \mathrm{K}_{\mathrm{i} \mu}=1.67 \mathrm{nM}[37]$ \\
\hline
\end{tabular}


A ligand with much higher estimated binding affinity was discovered which, like BDBM50033530, bears 3 H-bonds towards the target (fig 3). Seeing how the target is to stop PHIP(2) from interacting with acetyl-lysine residues, it would make sense that, should there be any link whatsoever between PHIP(2) and KOR, antagonists would have better binding affinity, explaining the better binding affinity estimations.
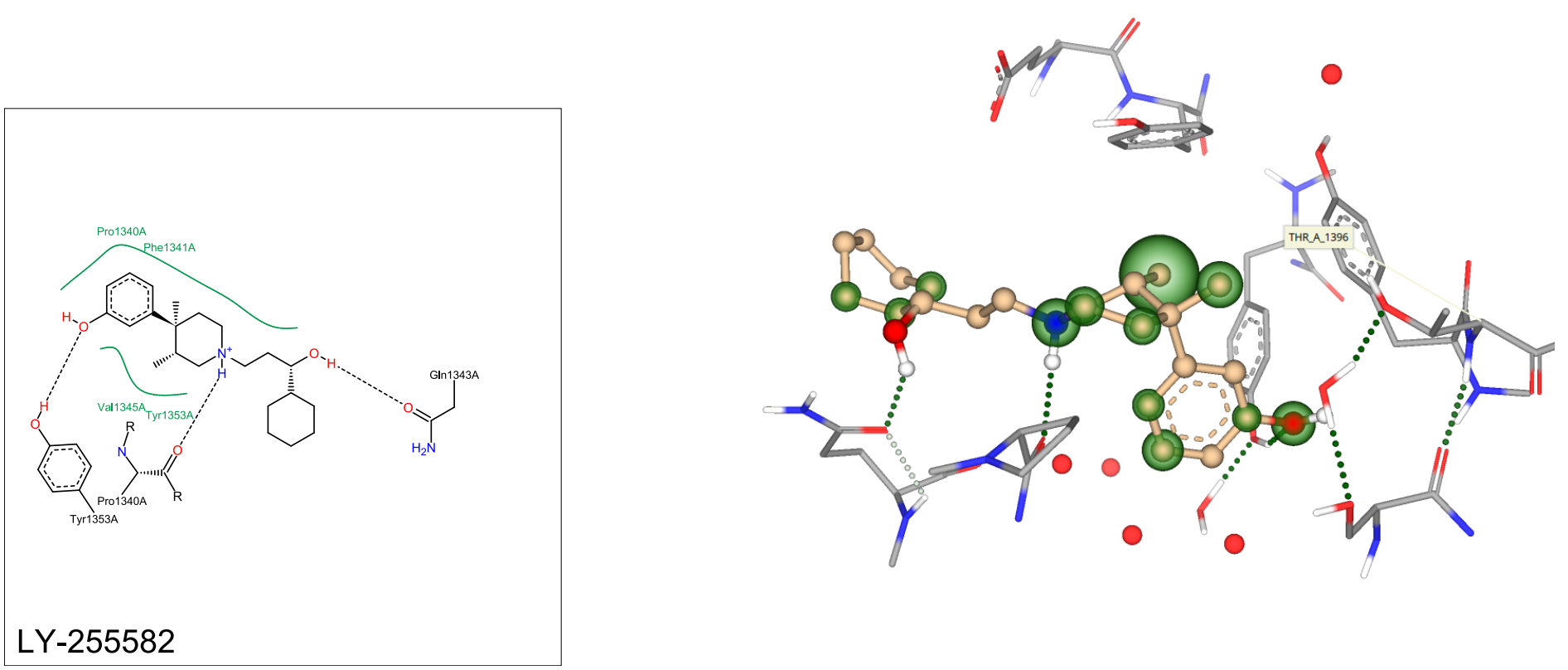

Figure 3: Three-dimensional docking view of LY-255582 in SeeSAR 

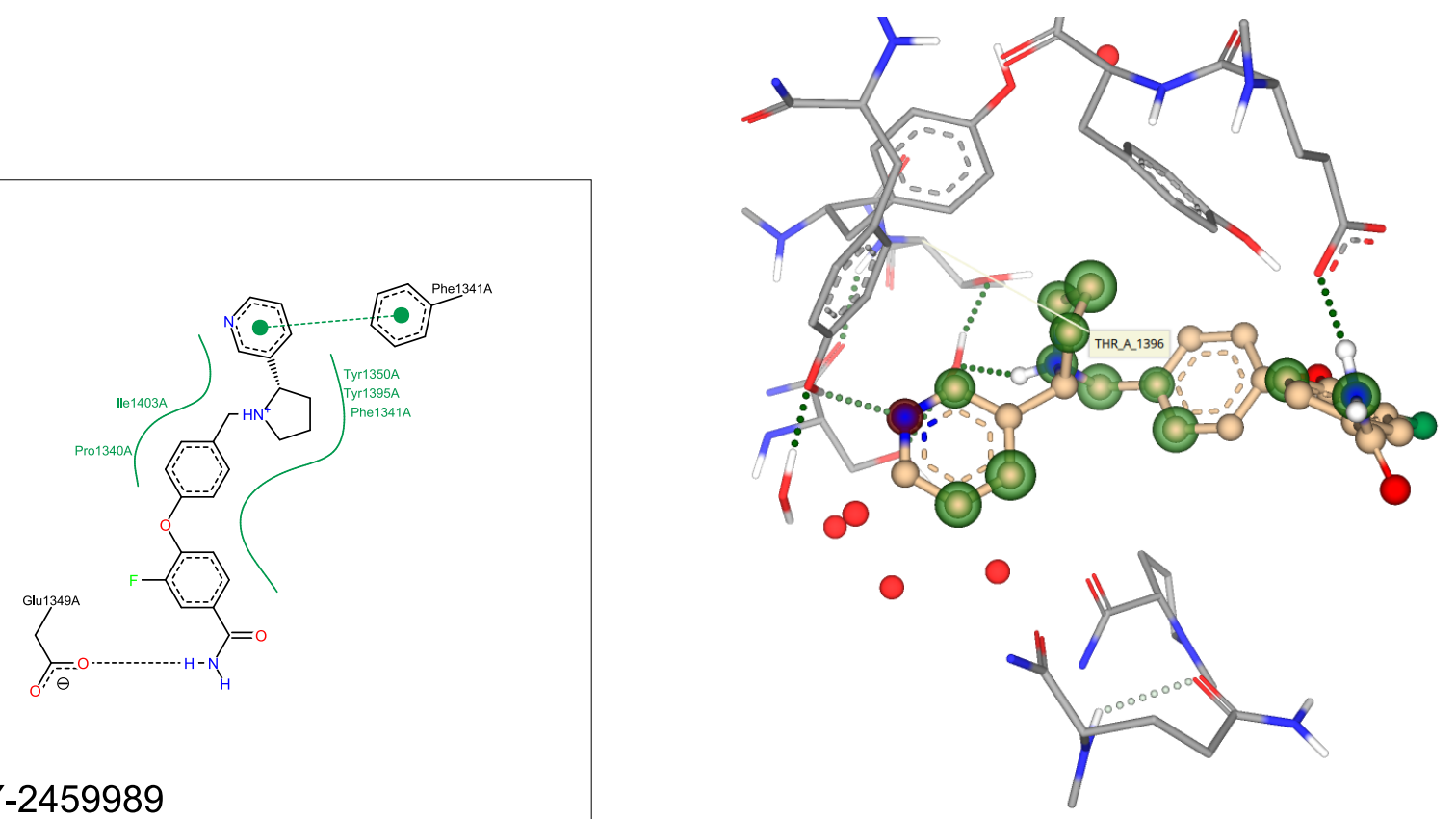

Figure 4: Three-dimensional docking view of LY-2459989 in SeeSAR
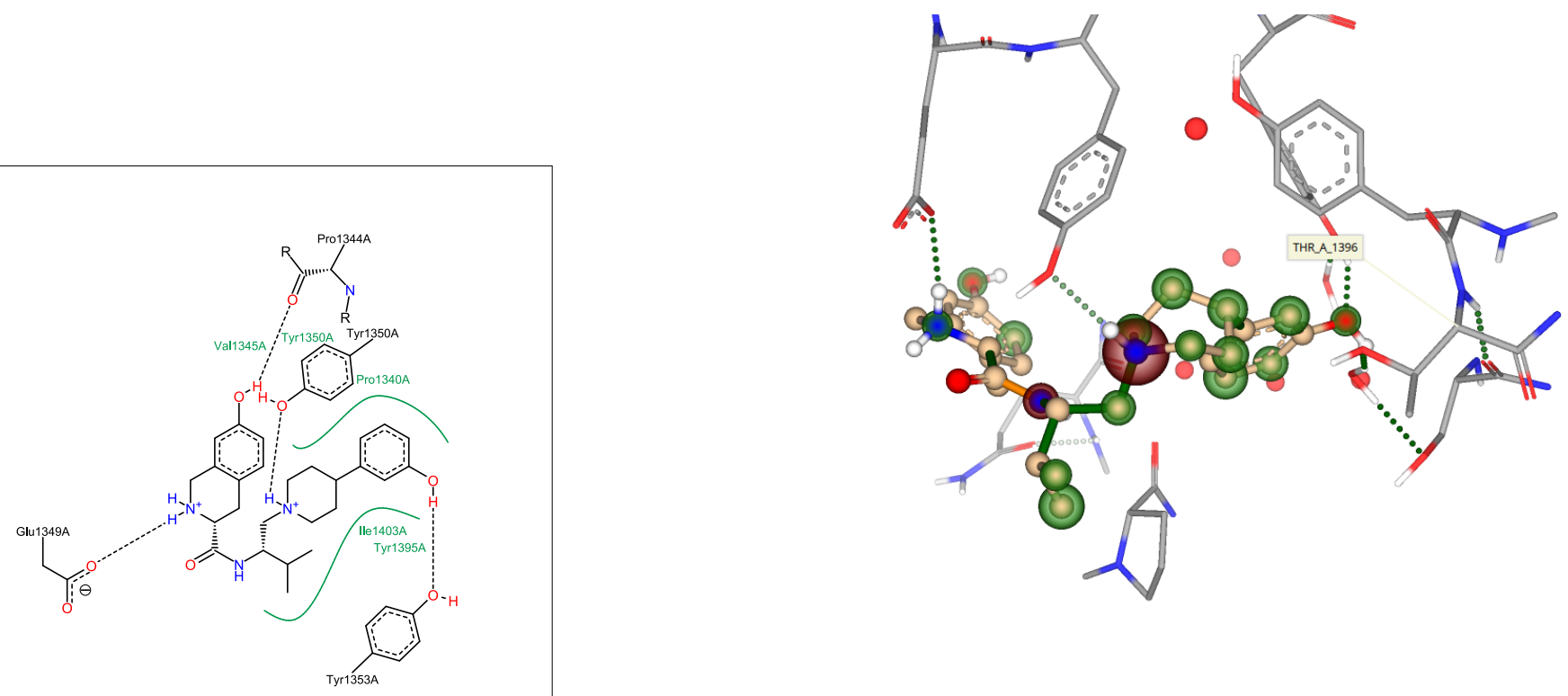

AT-076

Figure 5: Three-dimensional docking view of AT-076 in SeeSAR 
In the case of LY-2459989 (fig 4) and AT-076 (fig 5), there is an H-bond network with THR1396.

\section{Docking of LY-2459989 and LY-255582 against EP300}

Table 4: Docking of LY-2459989 and LY-255582 against EP300

\begin{tabular}{|c|c|c|c|}
\hline Ligand & $\begin{array}{c}\text { HYDE } \\
\text { estimated } \\
\text { affinity lower } \\
\text { bound }\end{array}$ & $\begin{array}{c}\text { HYDE } \\
\text { estimated } \\
\text { affinity upper } \\
\text { bound }\end{array}$ & H-bonds \\
\hline LY-2459989 & $82 \mathrm{nM}$ & $8.2 \mu \mathrm{M}$ & 3 \\
\hline LY-255582 & $1.3 \mu \mathrm{M}$ & $125 \mu \mathrm{M}$ & 2 \\
\hline
\end{tabular}

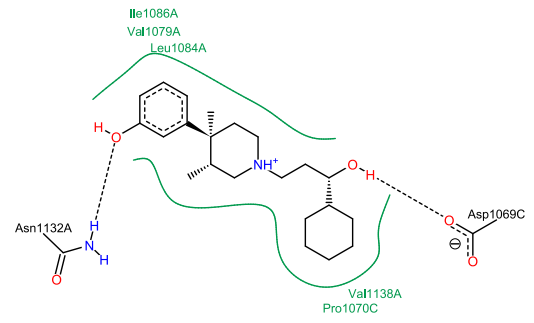

LY-255582 / EP300

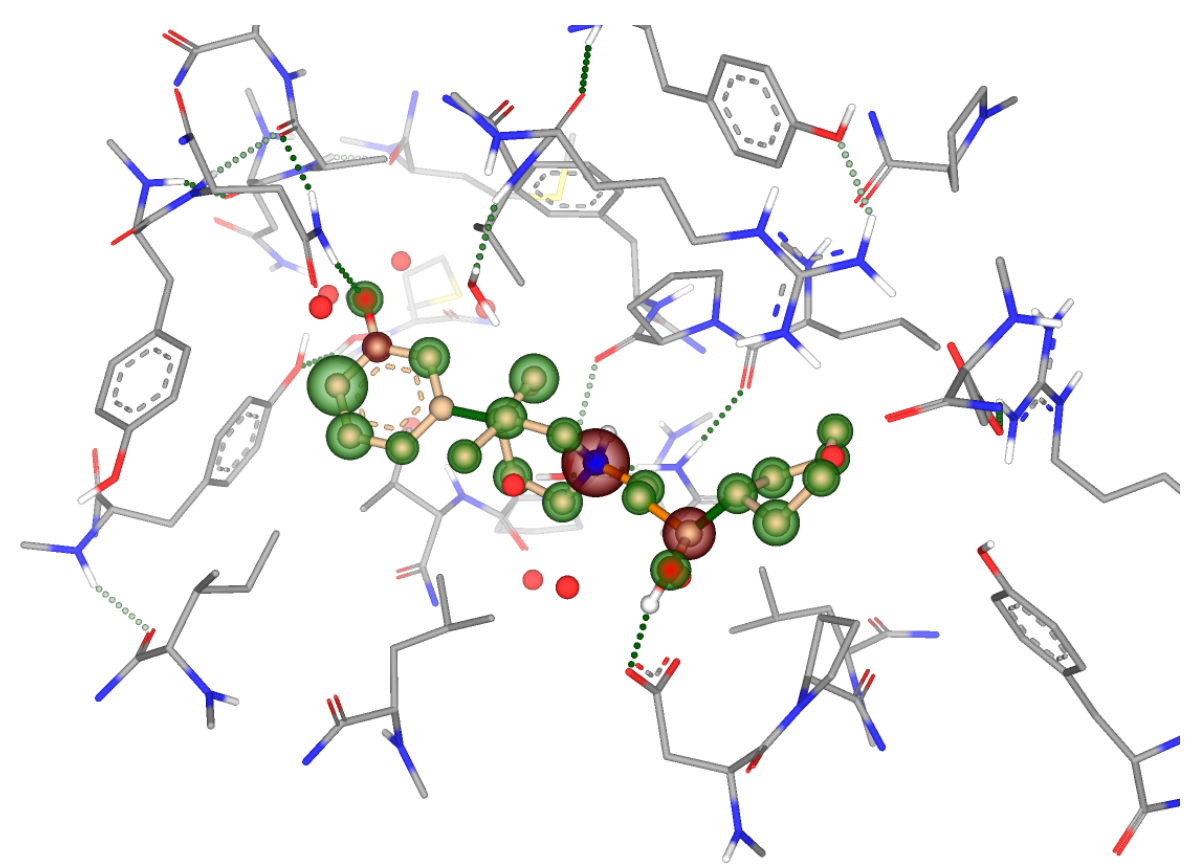

Figure 6: Three-dimensional docking view of LY-255582 against EP300 in SeeSAR 


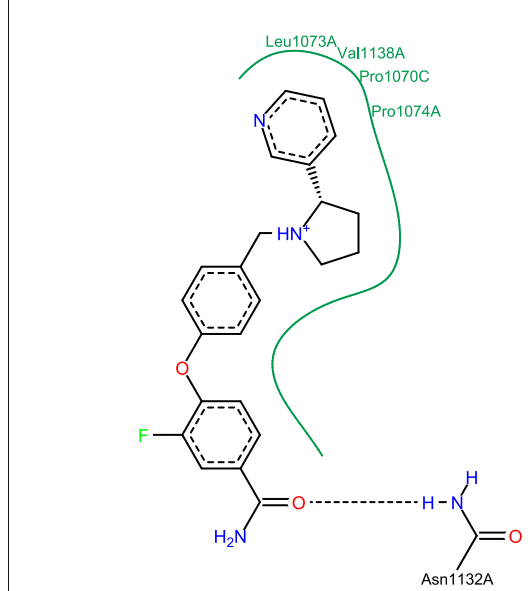

\section{LY-2459989 / EP300}

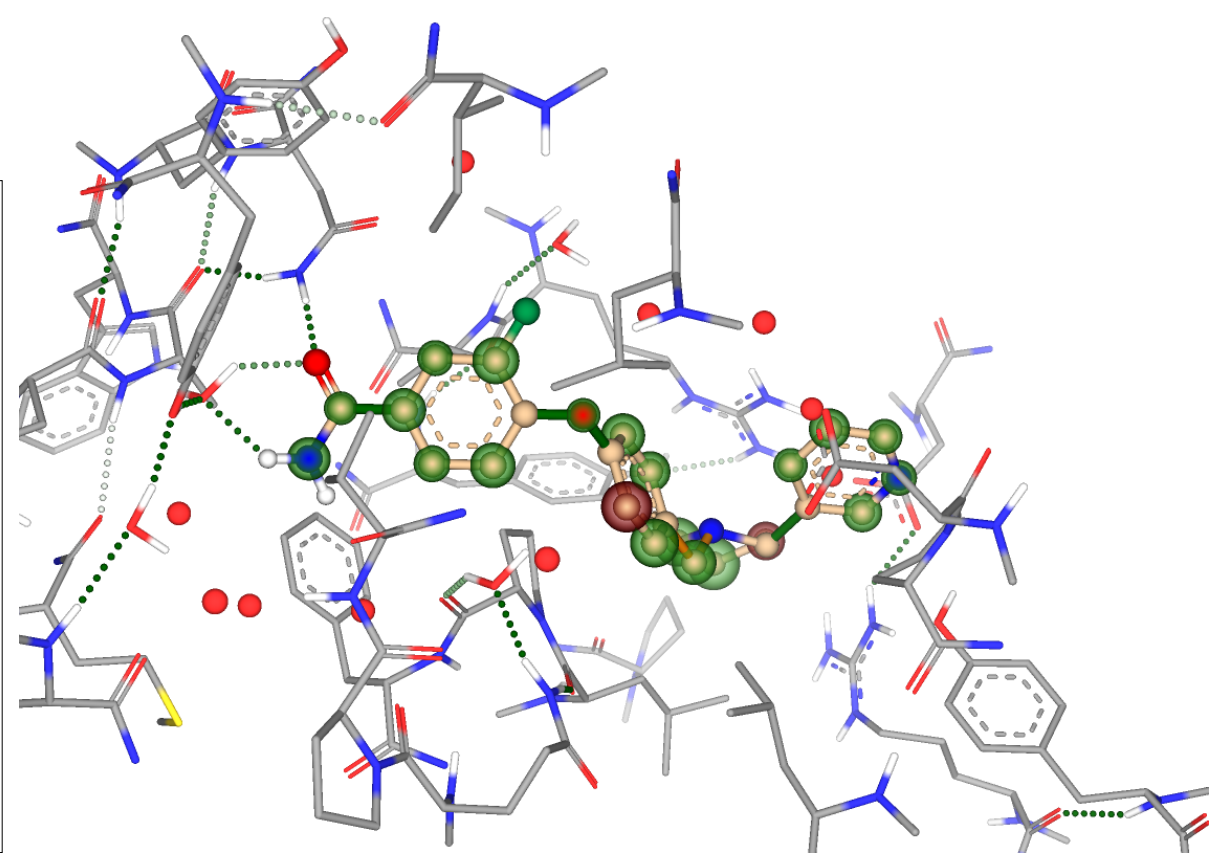

Figure 7: Three-dimensional docking view of LY-2459989 against EP300 in SeeSAR

The estimated affinities are similar to $\operatorname{PHIP}(2)$ for both ligands. With three H-bonds being exclusively one-sided and no $\pi$-interaction to hold it in place, the result is unreliable for LY-2459989. LY-255582, on the other hand, shows a solid support from both sides using H-bonds. This is unsurprising, as EP300 and $\operatorname{PHIP(2)~share~the~same~category[14].~}$

\section{Docking of LY-2459989 and LY-255582 against BRD9}

Table 5: Docking of LY-2459989 and LY-255582 against BRD9

\begin{tabular}{|c|c|c|c|c|}
\hline Ligand & $\begin{array}{c}\text { HYDE } \\
\text { estimated } \\
\text { affinity lower } \\
\text { bound } / \mathrm{nM}\end{array}$ & $\begin{array}{c}\text { HYDE } \\
\text { estimated } \\
\text { affinity upper } \\
\text { bound } / \mathrm{nM}\end{array}$ & Torsion colour & H-bonds \\
\hline \hline LY-255582 & 199 & 19778 & Green & 2 \\
\hline LY-2459989 & 1981 & 196853 & Green & 1 \\
\hline
\end{tabular}




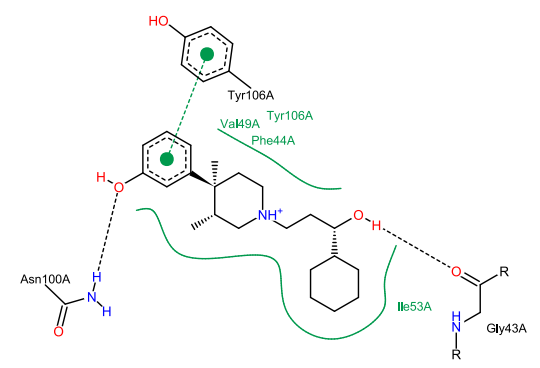

LY-255582 / BRD9

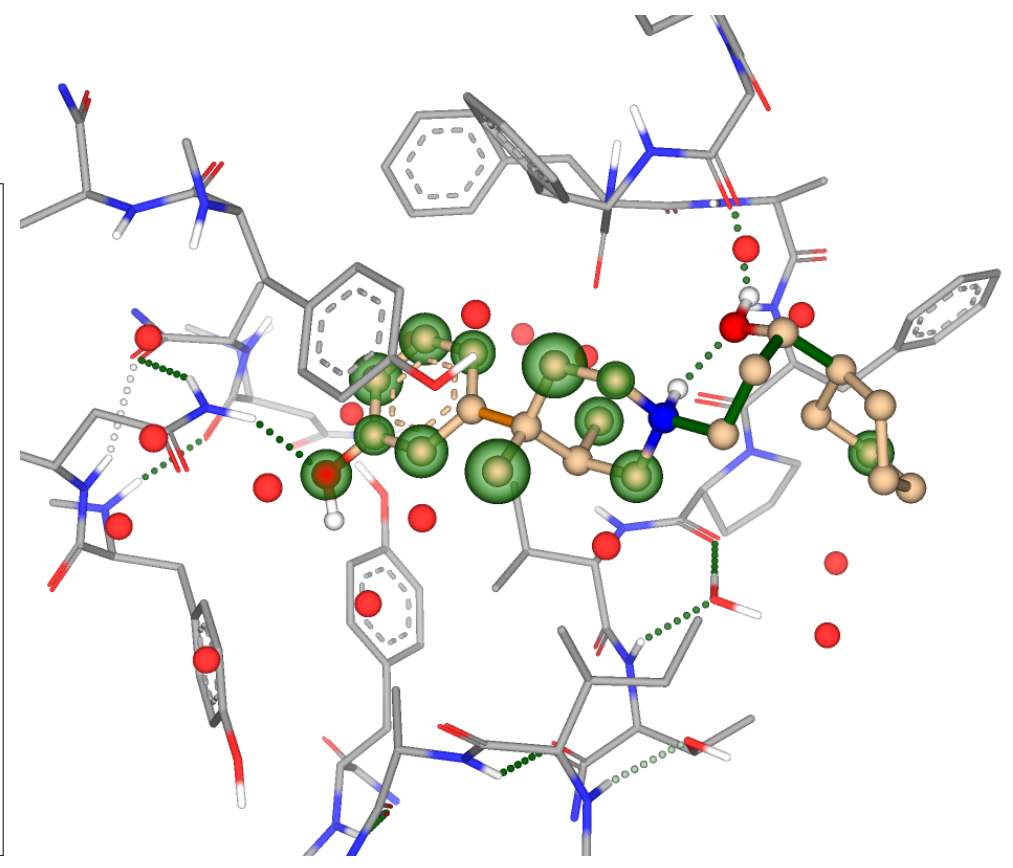

Figure 8: Three-dimensional docking view of LY-255582 against BRD9 in SeeSAR

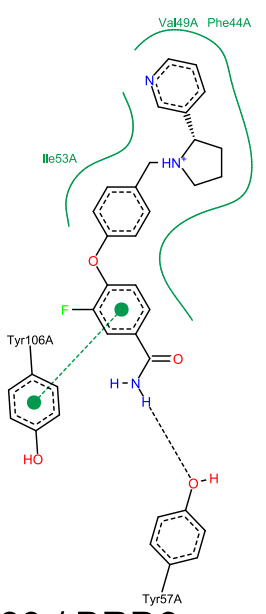

LY-2459989 / BRD9

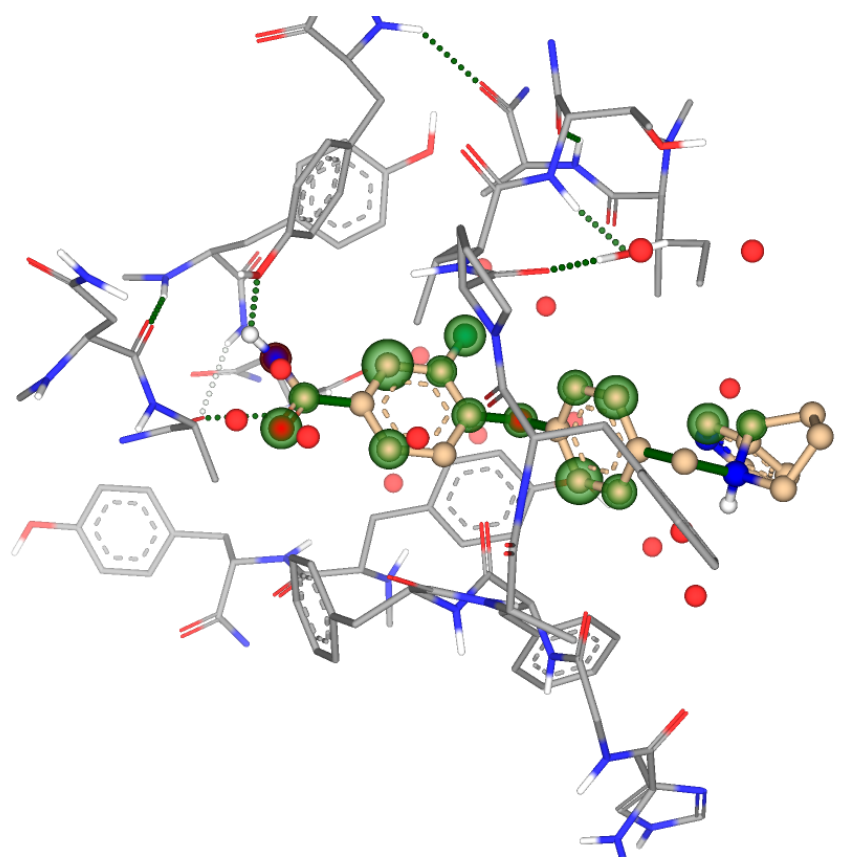

Figure 9: Three-dimensional docking view of LY-2459989 against BRD9 in SeeSAR 
The estimated affinity for both ligands is about half as good as for PHIP(2). LY-255582 is supported from both sides (notably by $\pi$-interaction from Tyr106A), although only using $2 \mathrm{H}$-bonds (rather than 3 in the case of PHIP(2)). In the case of LY-2459989, there is only one H-bond, making it very unbalanced, even though it there is $\pi$-interaction from Tyr106A. This is good, because BRD9 is not in the same category as $\operatorname{PHIP}(2)[14]$.

\section{Docking of LY-2459989 and LY-255582 against BRD1}

Table 6: Docking of LY-2459989 and LY-255582 against BRD1

\begin{tabular}{|c|c|c|c|}
\hline Ligand & $\begin{array}{c}\text { HYDE } \\
\text { estimated } \\
\text { affinity lower } \\
\text { bound }\end{array}$ & $\begin{array}{c}\text { HYDE } \\
\text { estimated } \\
\text { affinity upper } \\
\text { bound }\end{array}$ & H-bonds \\
\hline \hline LY-255582 & $26.8 \mu \mathrm{M}$ & $2.7 \mathrm{mM}$ & 3 \\
\hline LY-2459989 & $459 \mu \mathrm{M}$ & $45.6 \mathrm{mM}$ & 3 \\
\hline
\end{tabular}
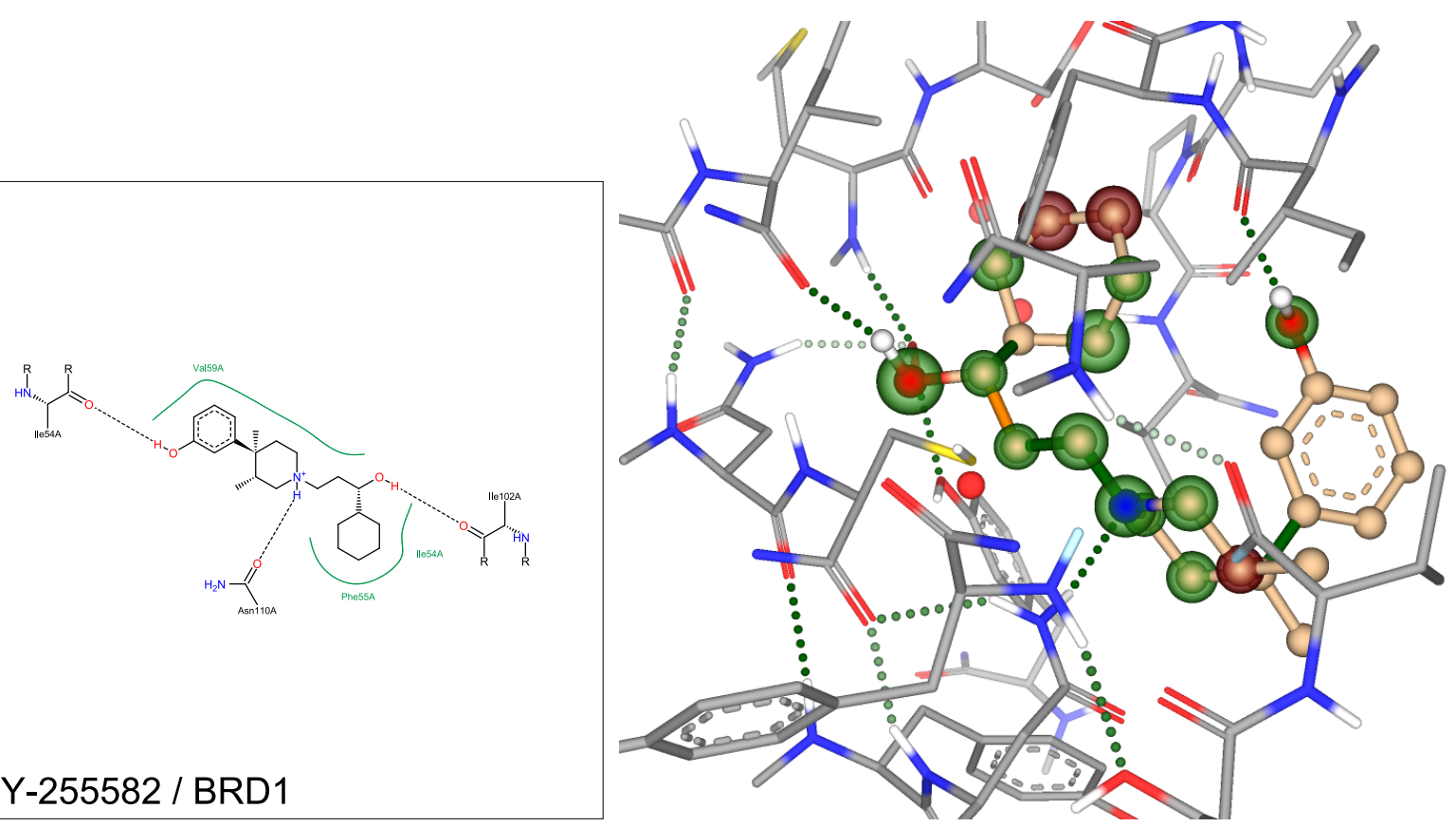

LY-255582 / BRD1

Figure 10: Three-dimensional docking view of LY-255582 against BRD1 in SeeSAR 

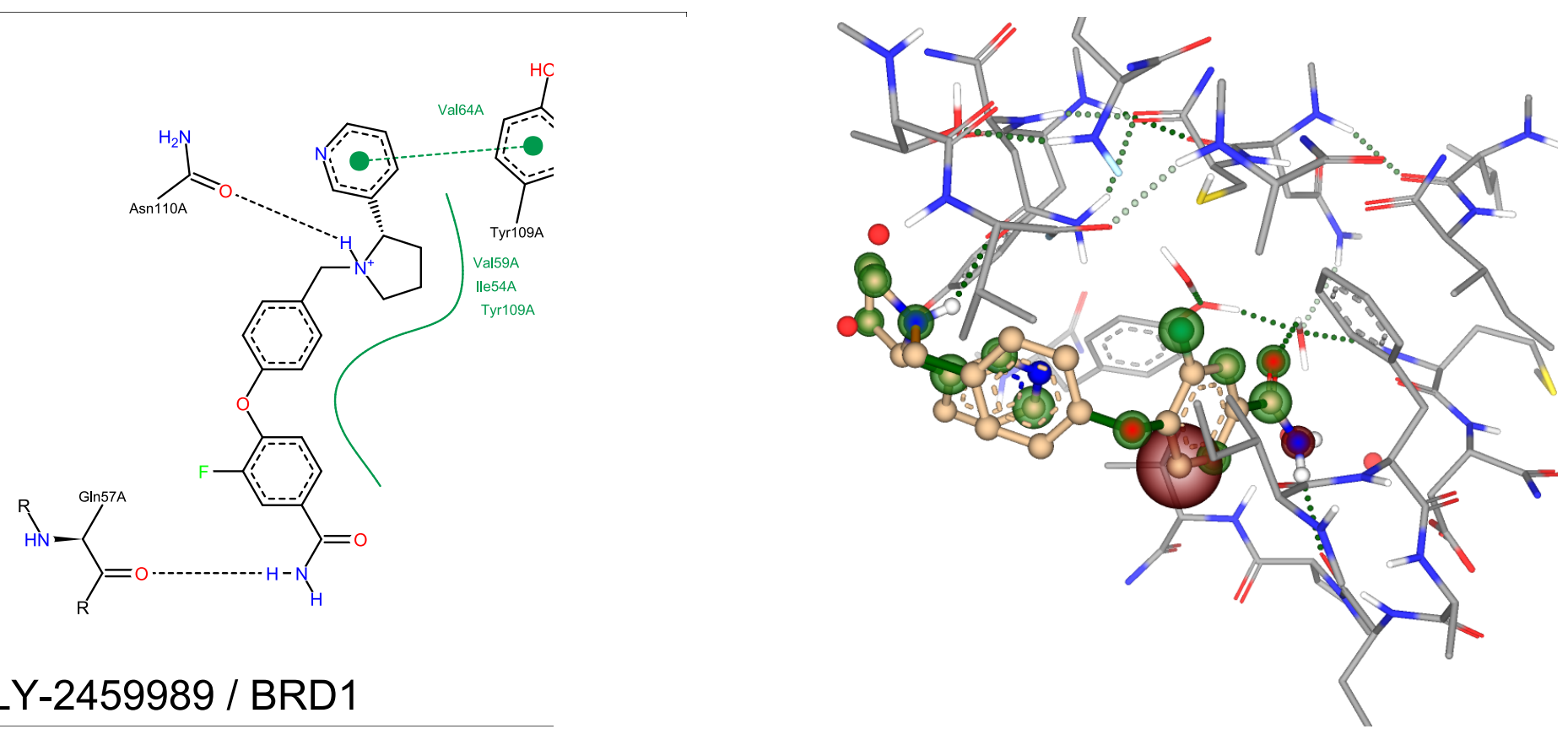

\section{LY-2459989 / BRD1}

Figure 11: Three-dimensional docking view of LY-2459989 against BRD1 in SeeSAR

The lower bound for the estimated affinity of LY-255582 is 290x weaker, and, LY-2459989 has a lower bound that's 440x weaker in comparison with the estimated lower bound for PHIP(2)[14]. Both candidates are well supported by 3 H-bonds and LY-2459989 has additional $\pi$-interaction from TYR109A. This is very good, because it shows selectivity towards PHIP(2).

\subsection{Docking of LY-2459989 and LY-255582 against BRD7}

Table 7: Docking of LY-2459989 and LY-255582 against BRD7

\begin{tabular}{|c|c|c|c|}
\hline Ligand & $\begin{array}{c}\text { HYDE } \\
\text { estimated } \\
\text { affinity lower } \\
\text { bound }\end{array}$ & $\begin{array}{c}\text { HYDE } \\
\text { estimated } \\
\text { affinity upper } \\
\text { bound }\end{array}$ & H-bonds \\
\hline LY-255582 & $648 \mathrm{nM}$ & $64.4 \mu \mathrm{M}$ & 2 \\
\hline LY-2459989 & $654 \mathrm{nM}$ & $65 \mu \mathrm{M}$ & 3 \\
\hline
\end{tabular}




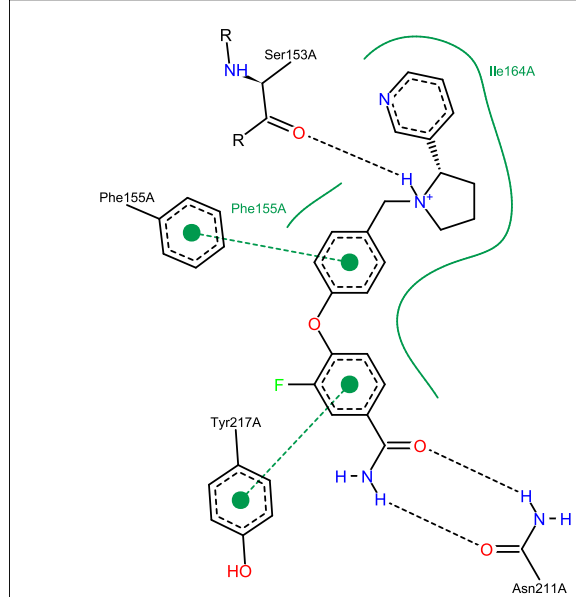

LY-2459989 / BRD7

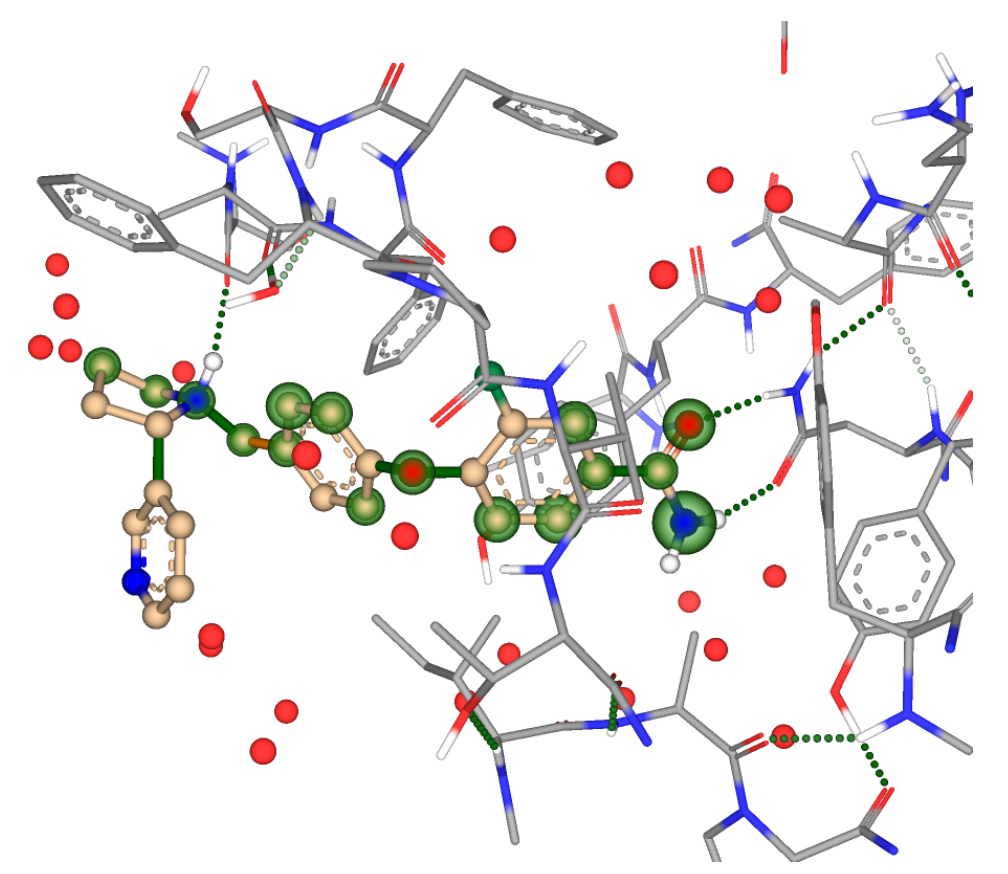

Figure 12: Three-dimensional docking view of LY-255582 against BRD7 in SeeSAR

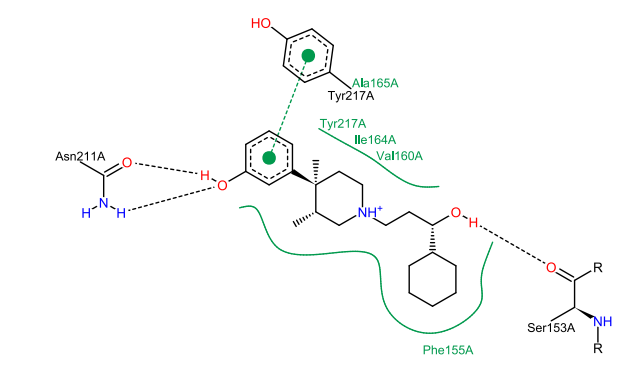

LY-255582 / BRD7

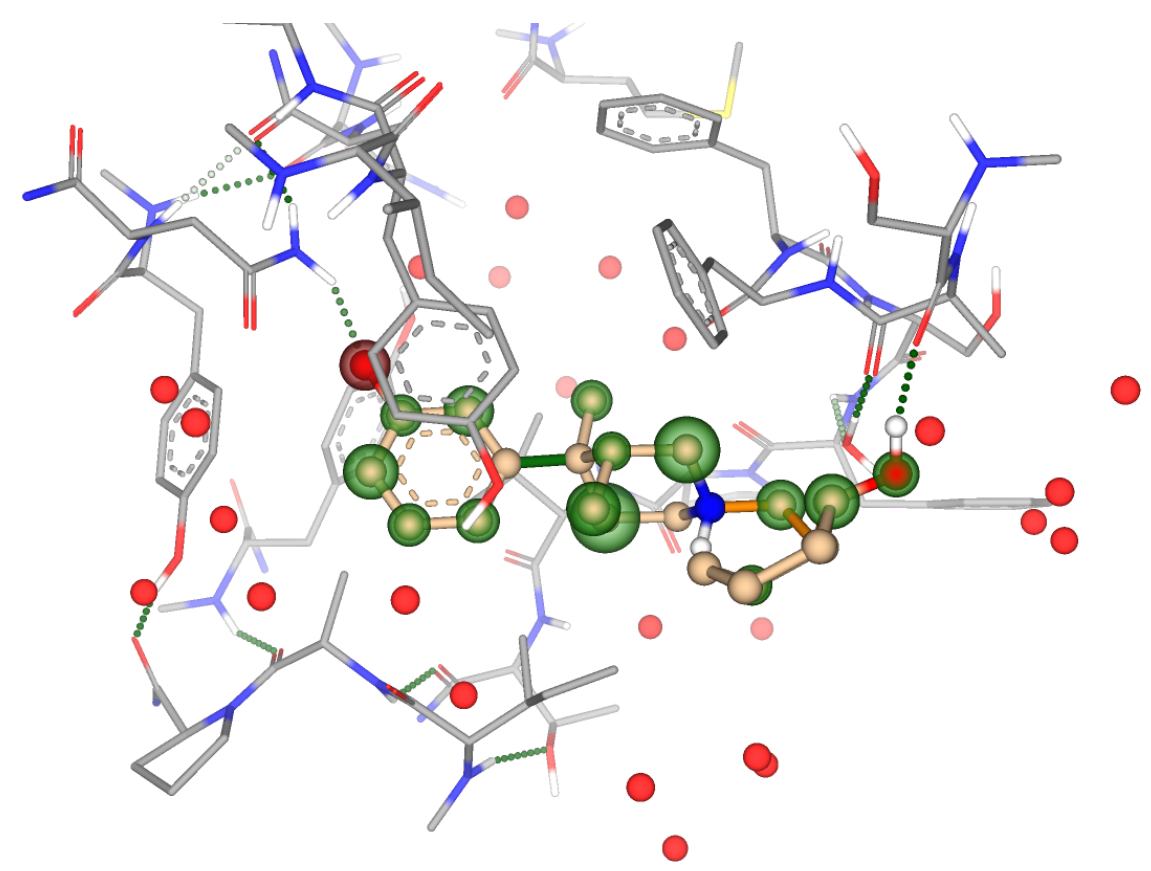

Figure 13: Three-dimensional docking view of LY-2459989 against BRD7 in SeeSAR 
The estimated affinities for LY-255582 is about 7 times weaker in comparison to PHIP(2) using 3 H-bonds and $2 \pi$ interaction from Phe155A and Tyr217A. The estimated affinity for LY-2459989 is 1.6x higher towards BRD7 in comparison to PHIP(2), although using 2 balanced H-bonds and $1 \pi$-interaction from TYR217A. Again, just like BRD9, these results are expected as PHIP(2) and BRD7 are not in the same category of bromodomains[14].

\subsection{Docking of LY-2459989 and LY-255582 against BRPF1}

Table 8: Docking of LY-2459989 and LY-255582 against BRPF1

\begin{tabular}{|c|c|c|c|}
\hline Ligand & $\begin{array}{c}\text { HYDE } \\
\text { estimated } \\
\text { affinity lower } \\
\text { bound }\end{array}$ & $\begin{array}{c}\text { HYDE } \\
\text { estimated } \\
\text { affinity upper } \\
\text { bound }\end{array}$ & H-bonds \\
\hline \hline LY-255582 & $2.6 \mu \mathrm{M}$ & $262 \mu \mathrm{M}$ & 3 \\
\hline LY-2459989 & $10.4 \mu \mathrm{M}$ & $1 \mathrm{mM}$ & 2 \\
\hline
\end{tabular}
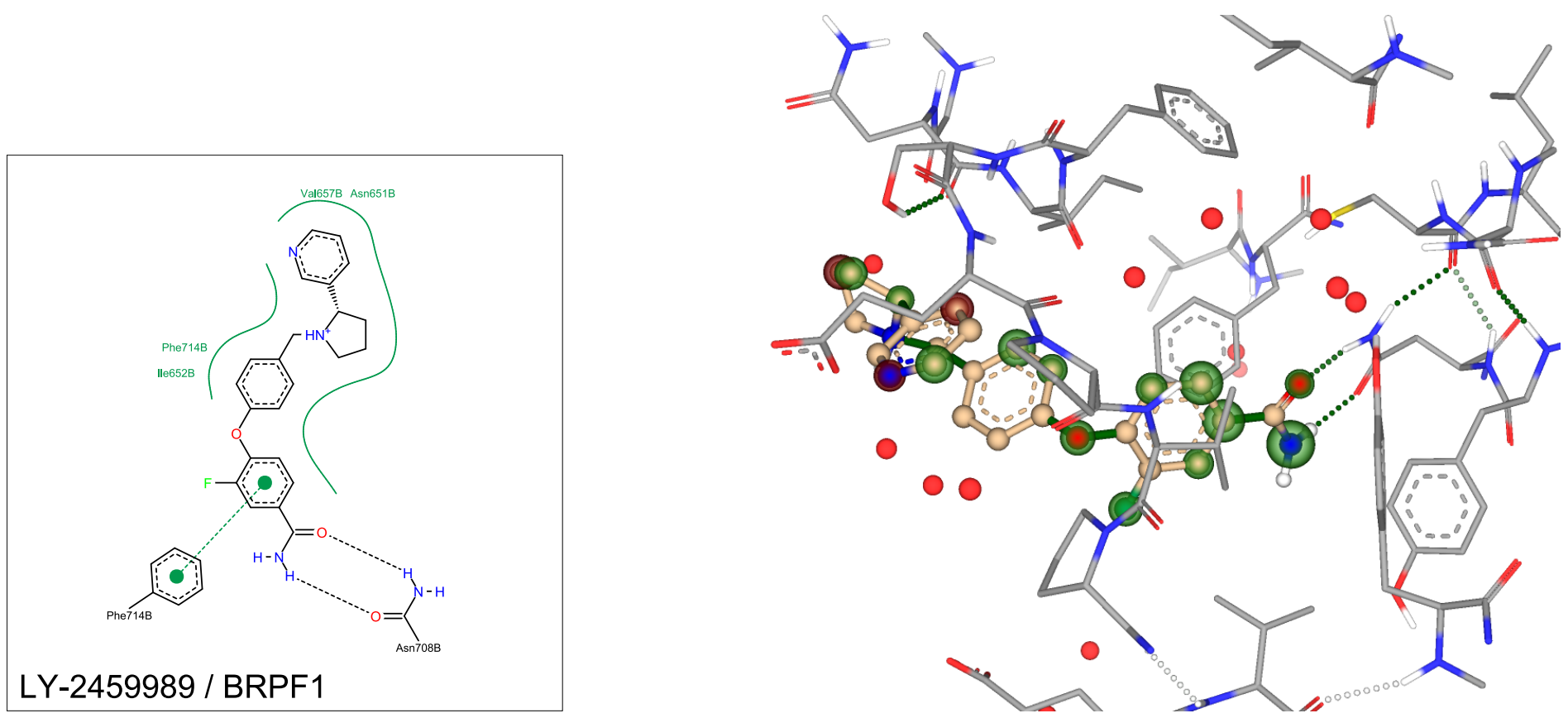

Figure 14: Three-dimensional docking view of LY-255582 against BRPF1 in SeeSAR 


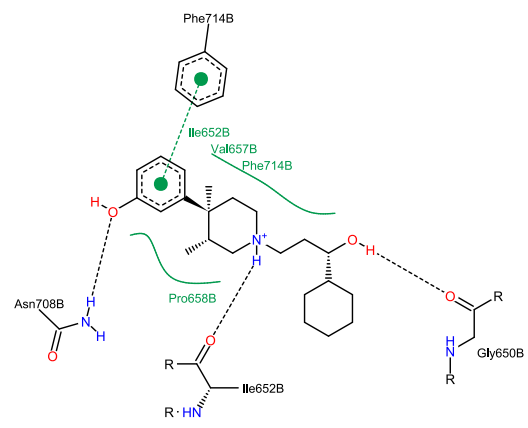

LY-255582 / BRPF1

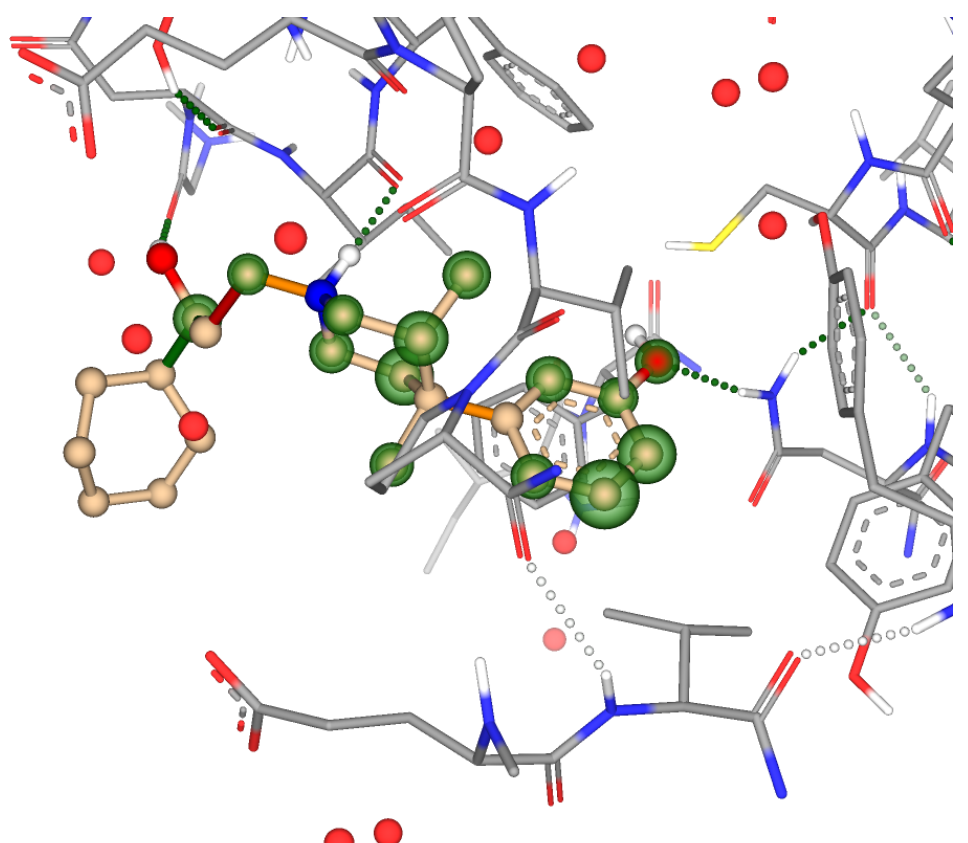

O

Figure 15: Three-dimensional docking view of LY-2459989 against BRPF1 in SeeSAR

For LY-2459989, both H-bonds and $\pi$-interaction (with Phe714B) are one-sided, providing no good scaffolding support, similar to the results towards EP300. This is not the case for LY-255582: 3 H-bonds, as well as a $\pi$-interaction with Phe714B. The binding affinities are more selective towards PHIP(2) than BRPF1. This selectivity is wanted, because BRPF1 is category IV and PHIP(2) is category III.[14]

\subsection{Docking of LY-2459989 and LY-255582 against CREBBP}

Table 9: Docking of LY-2459989 and LY-255582 against CREBBP

\begin{tabular}{|c|c|c|c|}
\hline Ligand & $\begin{array}{c}\text { HYDE } \\
\text { estimated } \\
\text { affinity lower } \\
\text { bound }\end{array}$ & $\begin{array}{c}\text { HYDE } \\
\text { estimated } \\
\text { affinity upper } \\
\text { bound }\end{array}$ & H-bonds \\
\hline \hline LY-255582 & $5.6 \mu \mathrm{M}$ & $555 \mu \mathrm{M}$ & 1 \\
\hline LY-2459989 & $19 \mu \mathrm{M}$ & $1.9 \mathrm{mM}$ & 2 \\
\hline
\end{tabular}




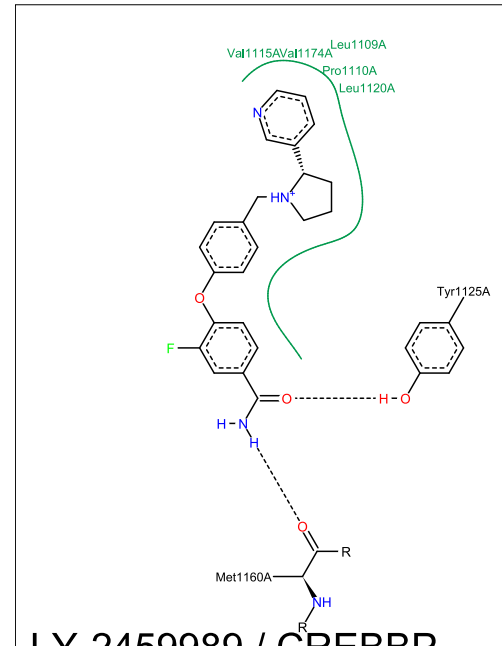

LY-2459989 / CREBBP

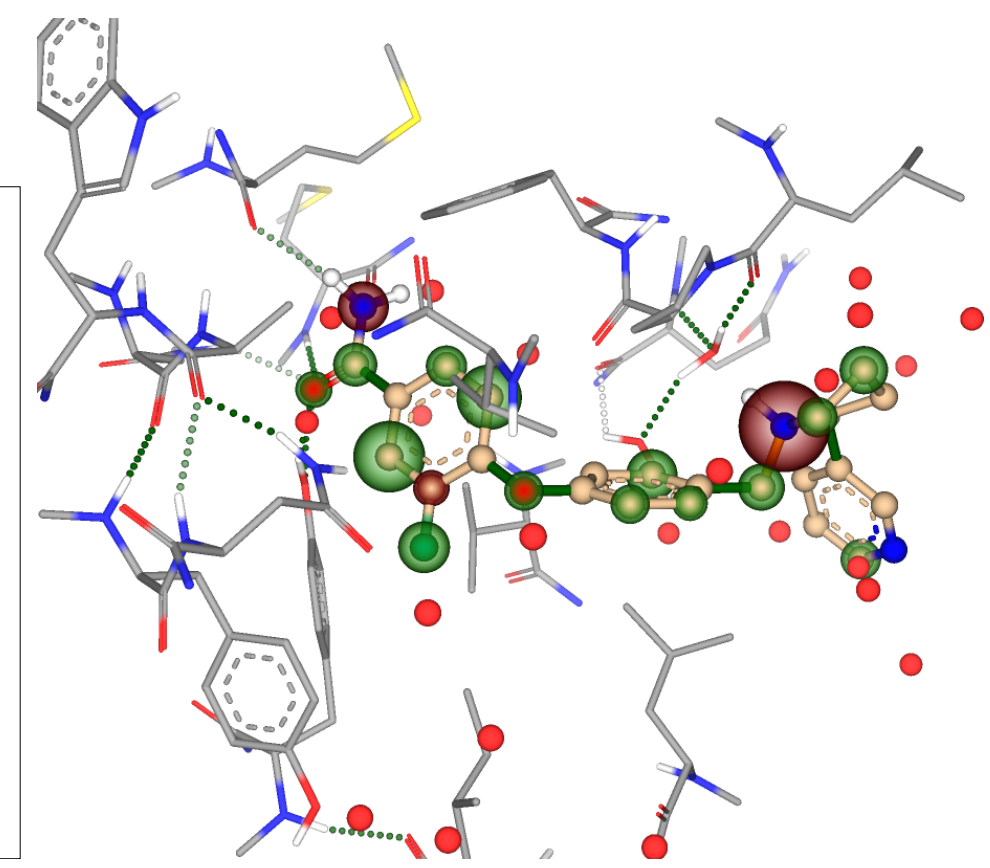

Figure 16: Three-dimensional docking view of LY-255582 against CREBBP in SeeSAR
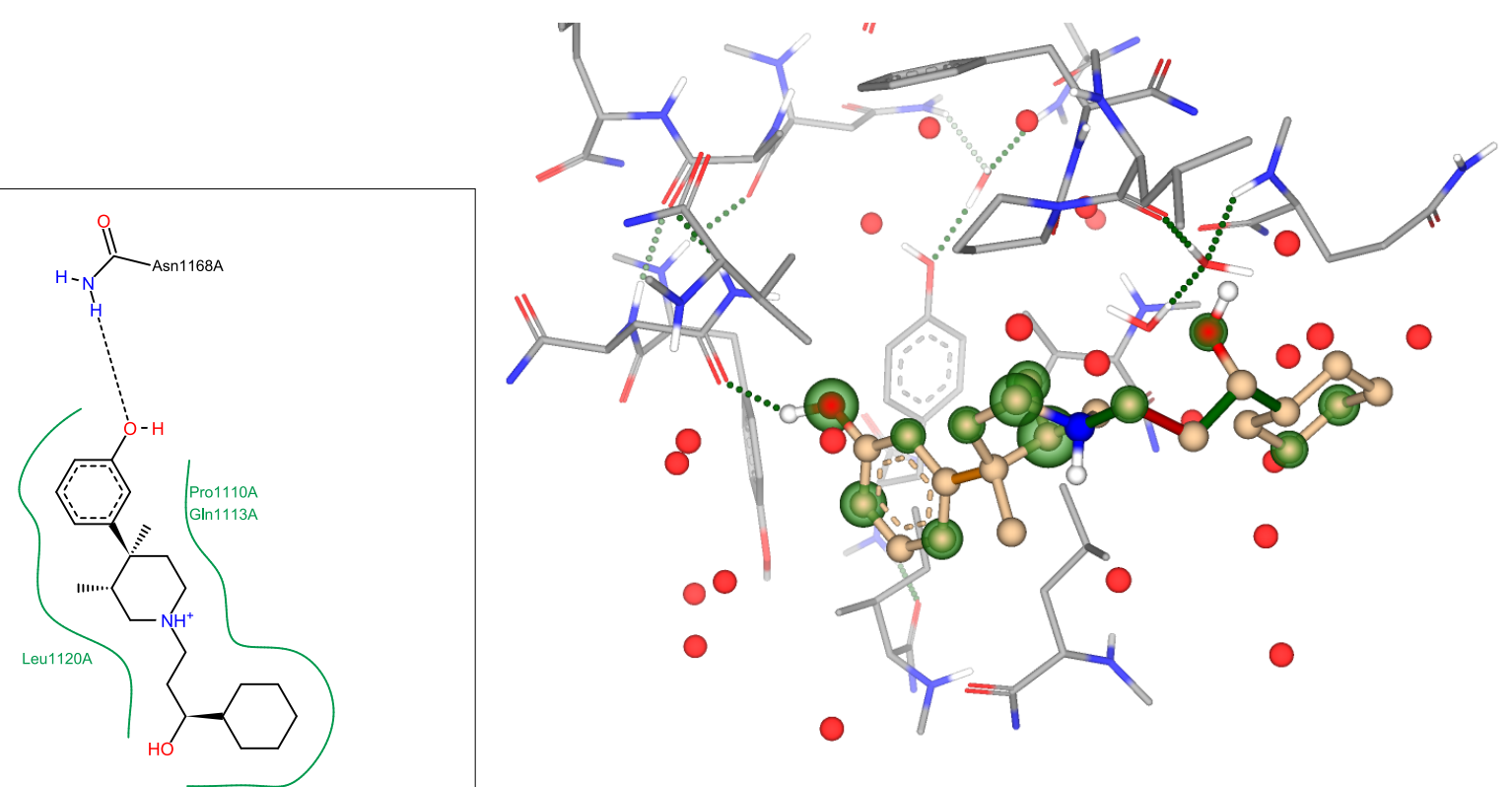

\section{LY-255582 / CREBBP}

Figure 17: Three-dimensional docking view of LY-2459989 against CREBBP in SeeSAR 
The binding affinities for both are not that great in comparison to $\mathrm{PHIP}(2)$, even though they are in the same category of bromodomains[14].

Docking of LY-2459989 and LY-255582 against BAZ2A

Table 10: Docking of LY-2459989 and LY-255582 against BAZ2A

\begin{tabular}{|c|c|c|c|}
\hline Ligand & $\begin{array}{c}\text { HYDE } \\
\text { estimated } \\
\text { affinity lower } \\
\text { bound }\end{array}$ & $\begin{array}{c}\text { HYDE } \\
\text { estimated } \\
\text { affinity upper } \\
\text { bound }\end{array}$ & H-bonds \\
\hline \hline LY-255582 & $24 \mu \mathrm{M}$ & $2.4 \mathrm{mM}$ & 3 \\
\hline LY-2459989 & $289 \mu \mathrm{M}$ & $28 \mathrm{mM}$ & 3 \\
\hline
\end{tabular}
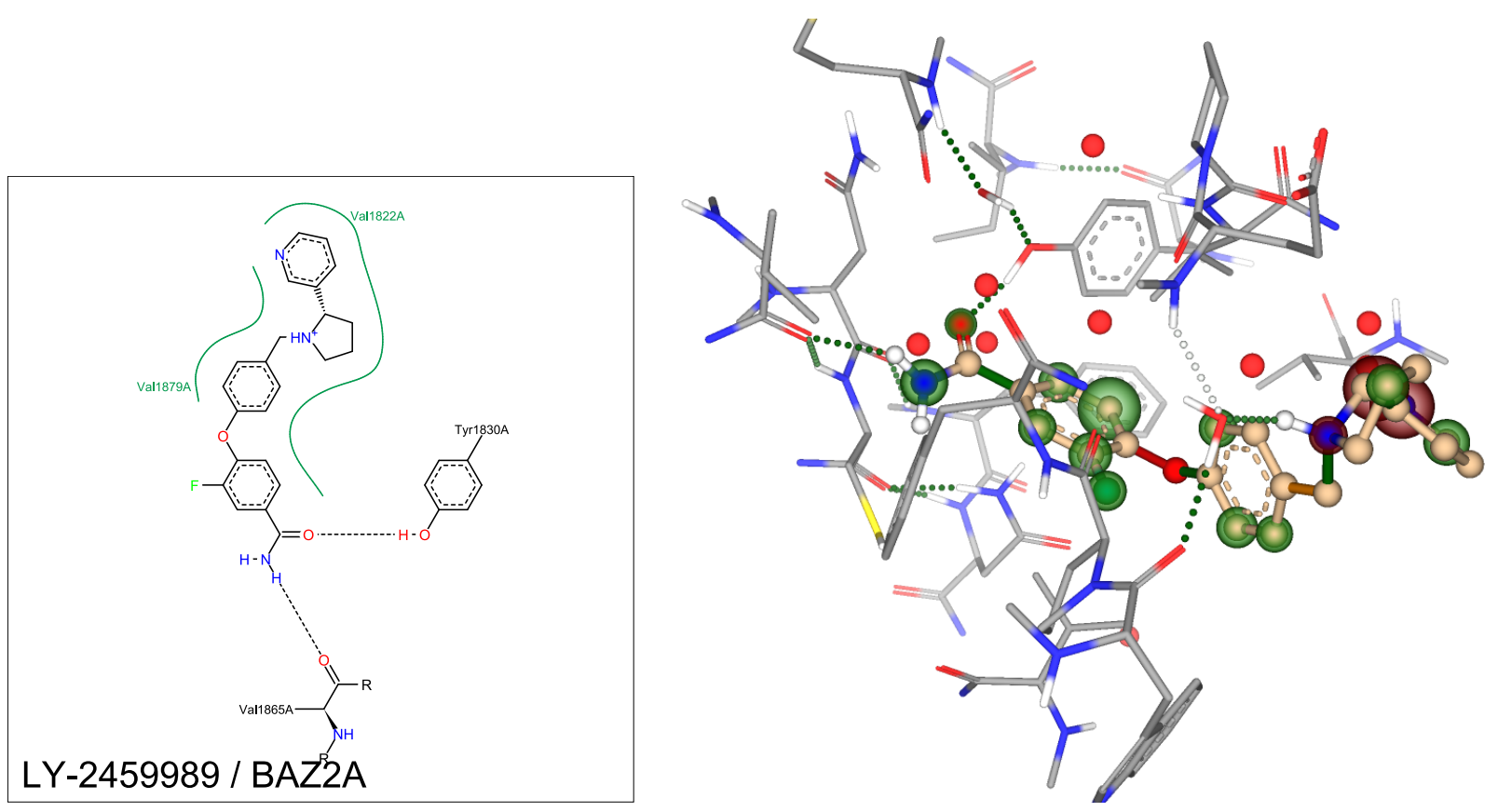

Figure 18: Three-dimensional docking view of LY-255582 against BAZ2A in SeeSAR 


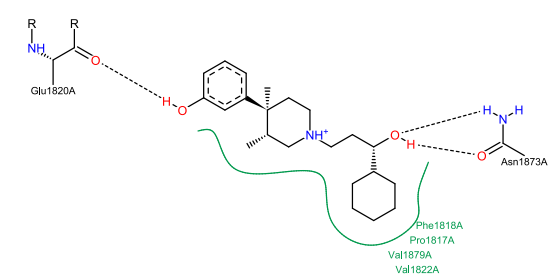

LY-255582 / BAZ2A

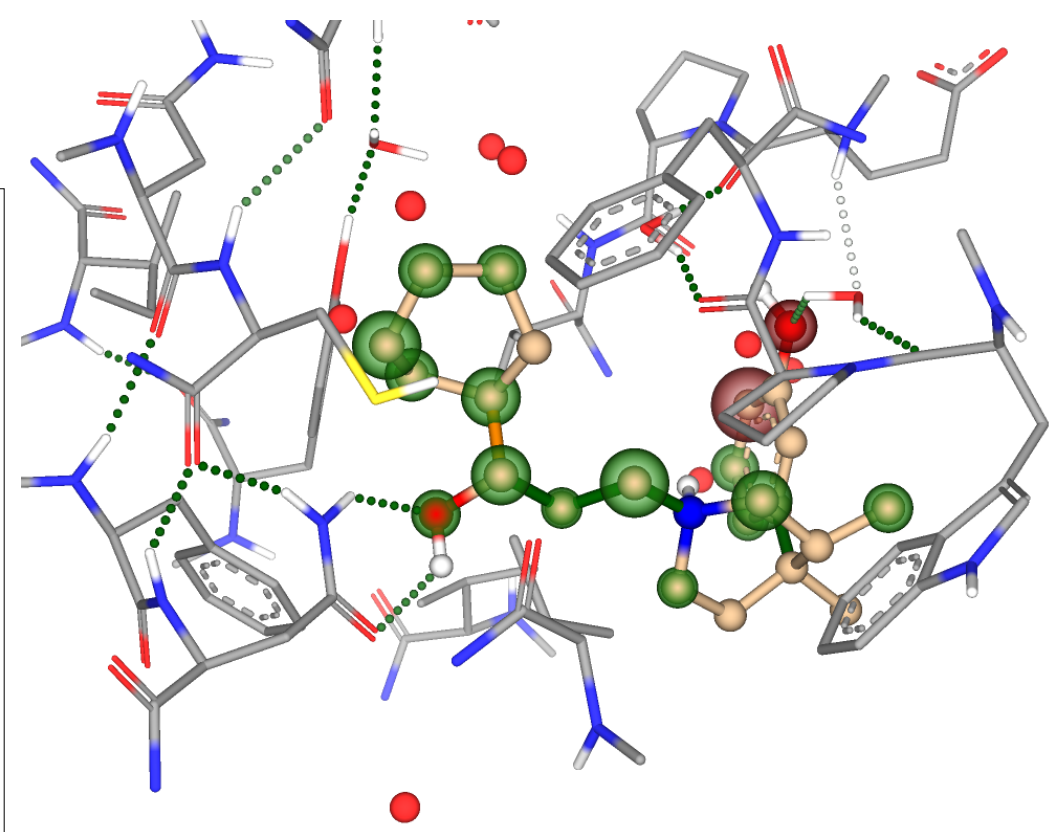

Figure 19: Three-dimensional docking view of LY-2459989 against BAZ2A in SeeSAR

In both cases, $2 \mathrm{H}$-bonds hold the molecules in place and the estimated binding affinities are over 250x lower than for PHIP(2). This selectivity is advantageous, seeing how PHIP(2) is category III, whereas BAZ2A is category V[14].

\section{Docking of LY-2459989 and LY-255582 against BAZ2B}

Table 11: Docking of LY-2459989 and LY-255582 against BAZ2B

\begin{tabular}{|c|c|c|c|}
\hline Ligand & $\begin{array}{c}\text { HYDE } \\
\text { estimated } \\
\text { affinity lower } \\
\text { bound }\end{array}$ & $\begin{array}{c}\text { HYDE } \\
\text { estimated } \\
\text { affinity upper } \\
\text { bound }\end{array}$ & H-bonds \\
\hline \hline LY-2459989 & $4.3 \mu \mathrm{M}$ & $427 \mu \mathrm{M}$ & 3 \\
\hline LY-255582 & $73 \mu \mathrm{M}$ & $7.3 \mathrm{mM}$ & 2 \\
\hline
\end{tabular}




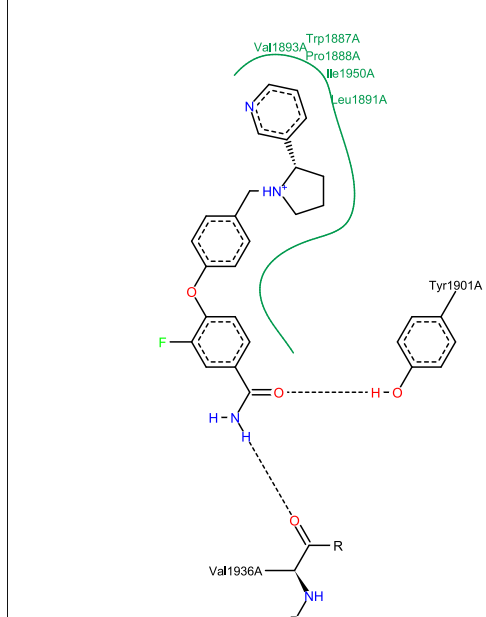

LY-2459989 / BAZ2B

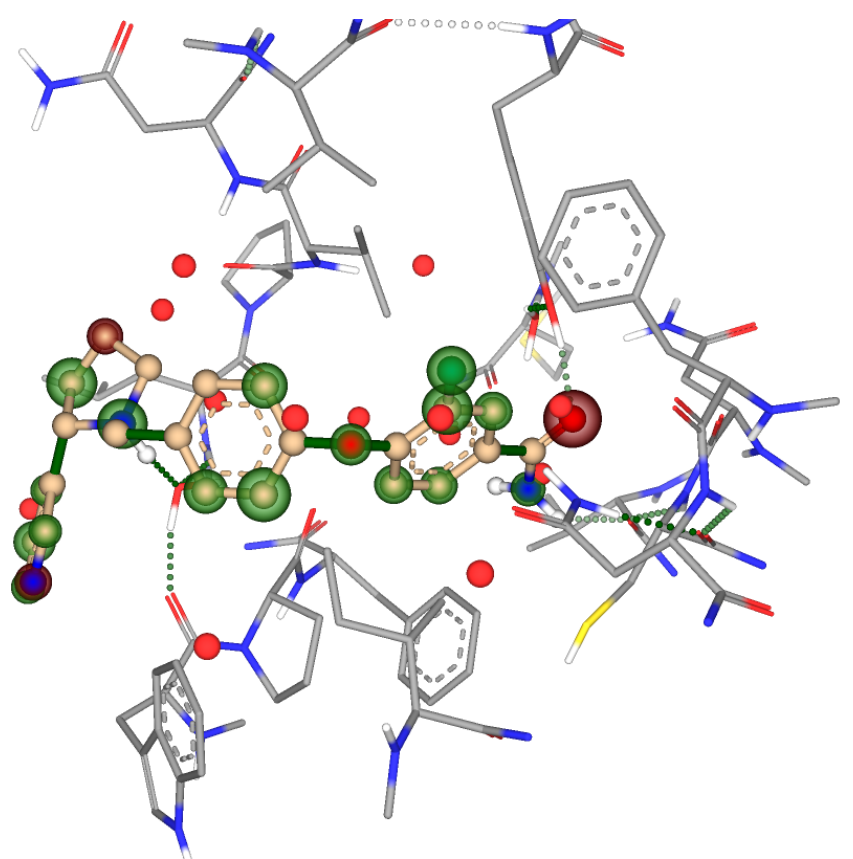

Figure 20: Three-dimensional docking view of LY-255582 against BAZ2B in SeeSAR

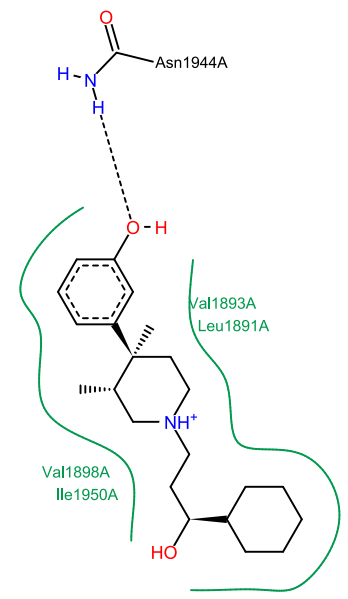

LY-255582 / BAZ2B

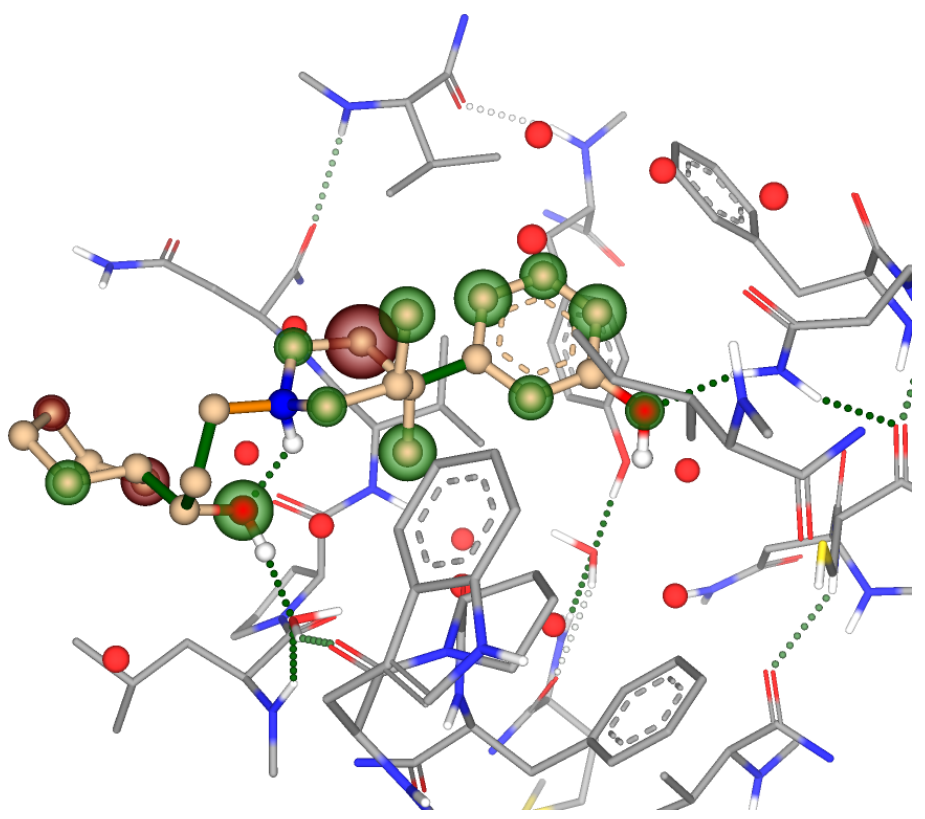

Figure 21: Three-dimensional docking view of LY-2459989 against BAZ2B in SeeSAR 
Besides the estimated binding affinities being at least 40x weaker in comparison to PHIP(2), desolvation is the major contributor for in both cases, shown using distances between the ligands and the water molecules. In both cases, we get very disappointing results including many red coronas. This selectivity towards PHIP(2) over BAZ2B is good because PHIP(2) is category III and BAZ2B is category V.[14]

\section{Docking of published PHIP(2) hits against KOR PDB 4DJH}

In order for there to be a link between KOR and PHIP(2), confirmed ligands for PHIP(2) must demonstrate good estimated binding affinity towards KOR, preferrably using the same residues being used to hold KOR antagonists in place. In this case, we chose PDB 4DJH chain A, which holds JDTic in place by interaction with residues VAL134, ASP138, MET142, and ILE294. Thus, we proceeded to dock all 7 currently published ligands, displaying the ligand of reference in chain A of PDB 4DJH[38], since that's where binding with JDTic elicits an antagonistic response.

Table 12: Docking results of PHIP(2) ligands against KOR PDB 4DJH

\begin{tabular}{|c|c|c|c|c|c|c|c|}
\hline Ligand & $\begin{array}{c}\text { HYDE } \\
\text { estimated } \\
\text { affinity } \\
\text { lower } \\
\text { bound } \\
\text { (KOR) }\end{array}$ & $\begin{array}{c}\text { HYDE } \\
\text { estimated } \\
\text { affinity } \\
\text { upper } \\
\text { bound } \\
\text { (KOR) }\end{array}$ & $\mathrm{K}_{\mathrm{iPHIP}(2) \exp }$ & $\begin{array}{c}\mathrm{H}- \\
\text { bonds }\end{array}$ & $\begin{array}{c}\text { ASP } \\
138\end{array}$ & $\begin{array}{c}\text { MET } \\
142\end{array}$ & $\begin{array}{c}\text { ILE } \\
294\end{array}$ \\
\hline FMOOA463 & $142 \mathrm{nM}$ & $14 \mu \mathrm{M}$ & $68 \mu \mathrm{M}$ & 1 & $\sqrt{ }$ & $\sqrt{ }$ & $\sqrt{ }$ \\
\hline XTS942 & $222 \mathrm{nM}$ & $22 \mu \mathrm{M}$ & $768 \mu \mathrm{M}$ & 2 & $\sqrt{ }$ & $\sqrt{ }$ & \\
\hline FMOOA322a & $1.6 \mu \mathrm{M}$ & $161 \mu \mathrm{M}$ & $190 \mu \mathrm{M}$ & 2 & $\sqrt{ }$ & & $\sqrt{ }$ \\
\hline FMOMB76b & $13 \mu \mathrm{M}$ & $1.3 \mathrm{mM}$ & $>5 \mathrm{mM}$ & 1 & $\sqrt{ }$ & & $\sqrt{ }$ \\
\hline FMOSA1515 & $28 \mu \mathrm{M}$ & $2.8 \mathrm{mM}$ & $269 \mu \mathrm{M}$ & 0 & & & \\
\hline FMOSA1544 & $90 \mu \mathrm{M}$ & $9 \mathrm{mM}$ & $588 \mu \mathrm{M}$ & 2 & $\sqrt{ }$ & $\sqrt{ }$ & $\sqrt{ }$ \\
\hline
\end{tabular}




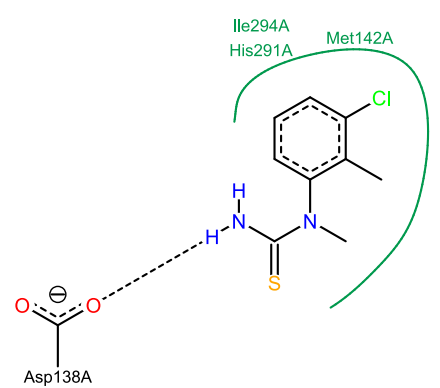

FMOOA463 / KOR

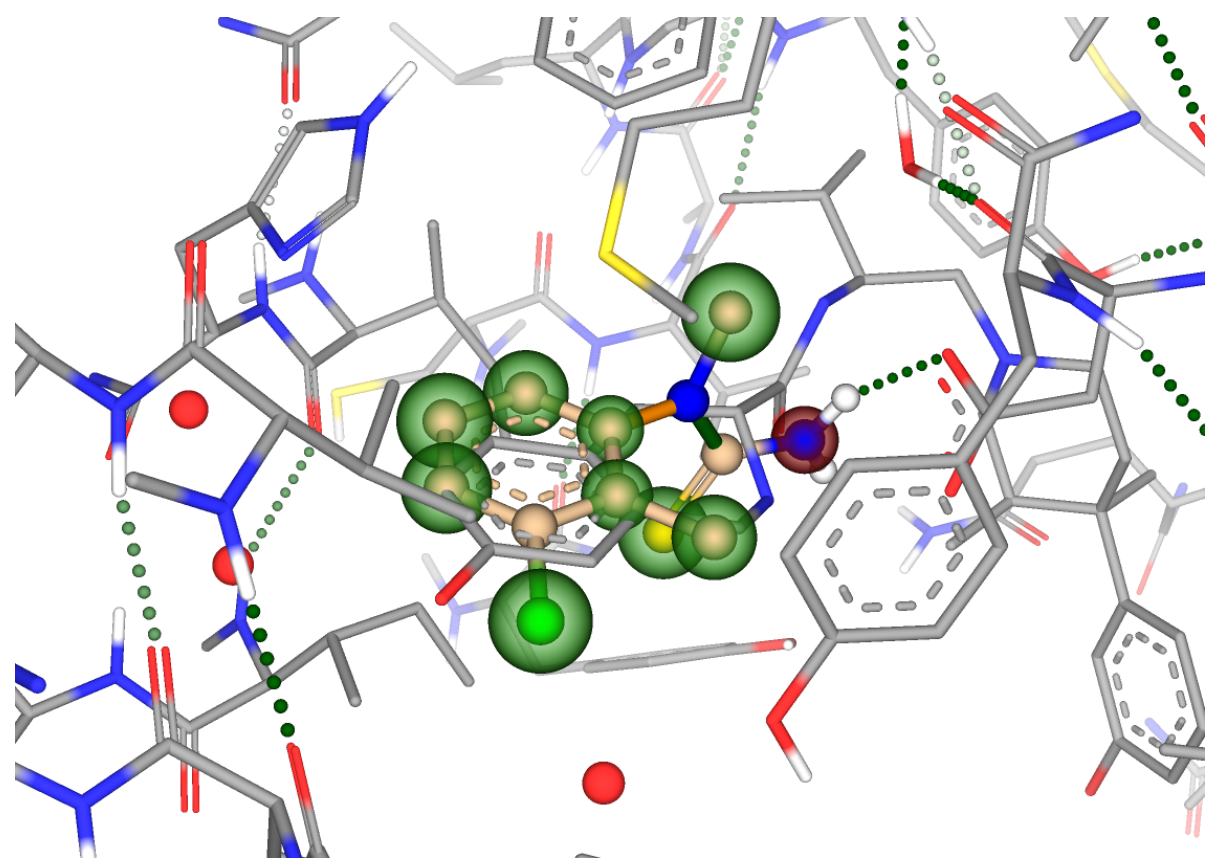

Figure 22: Three-dimensional docking view of FMOOA463 against KOR over JDTic as reference in SeeSAR

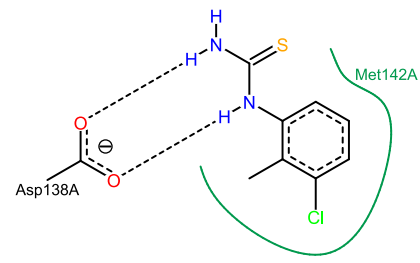

XTS942 / KOR

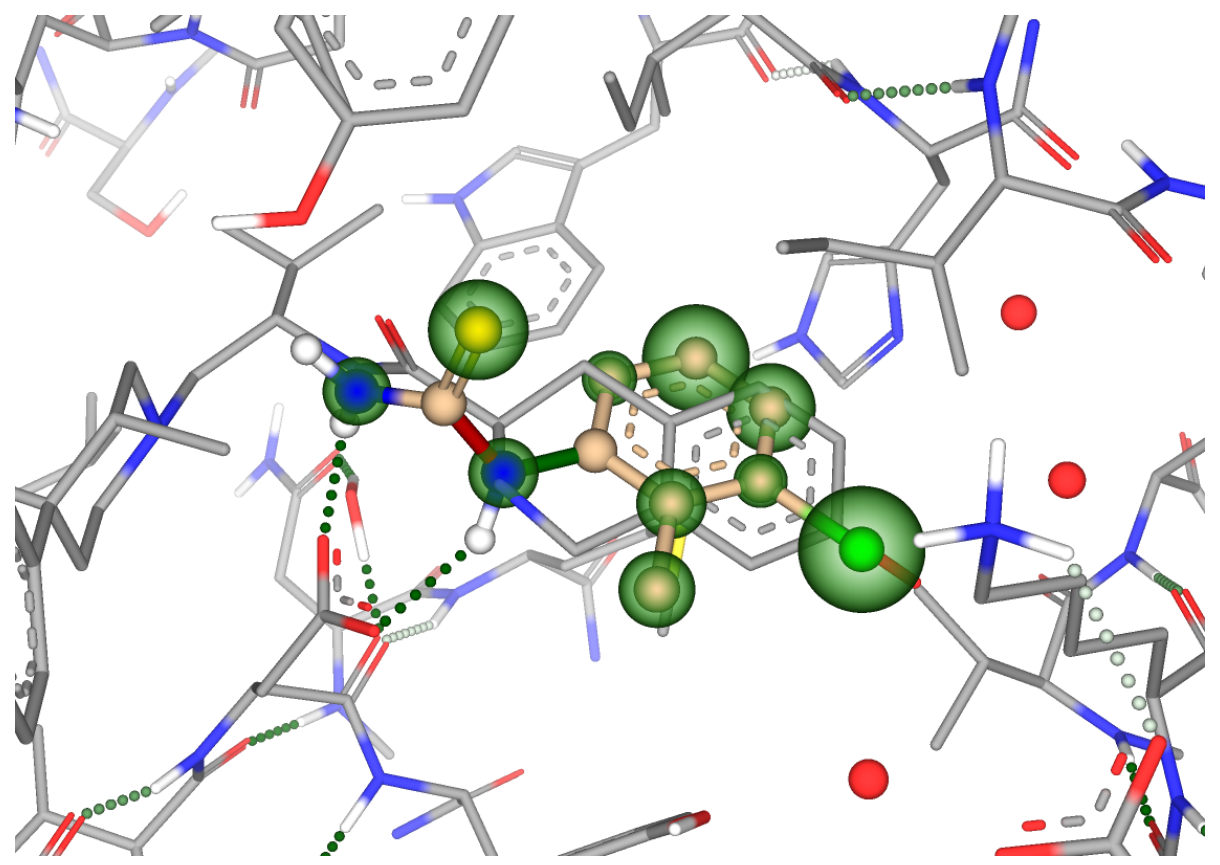

Figure 23: Three-dimensional docking view of XTS942 against KOR over JDTic as reference in SeeSAR 


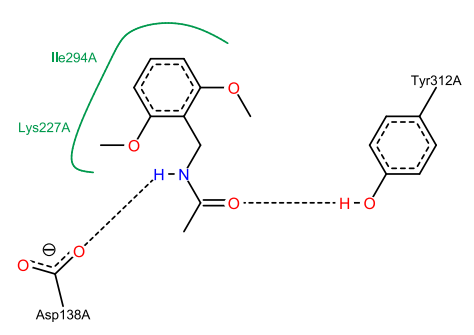

FMOOA322a / KOR

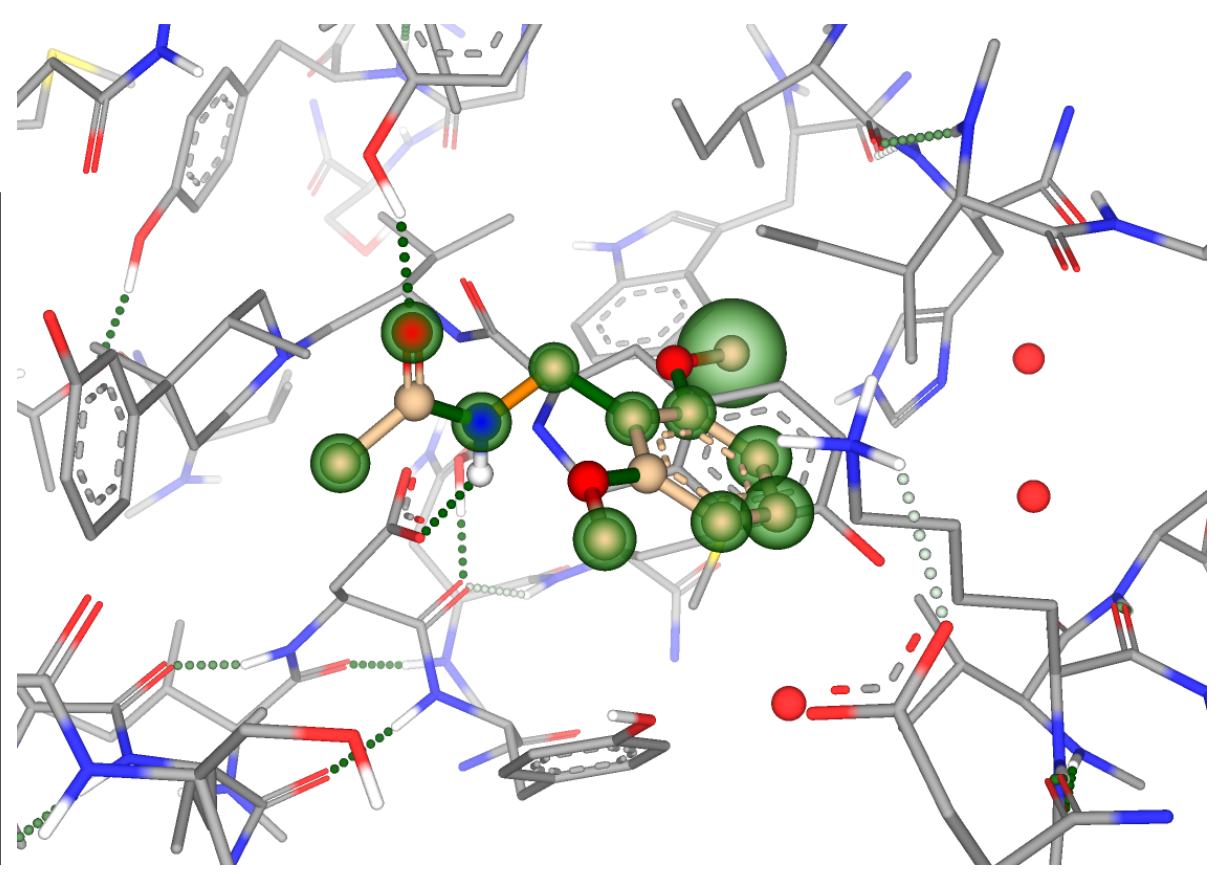

Figure 24: Three-dimensional docking view of FMOOA322a against KOR over JDTic as reference in SeeSAR

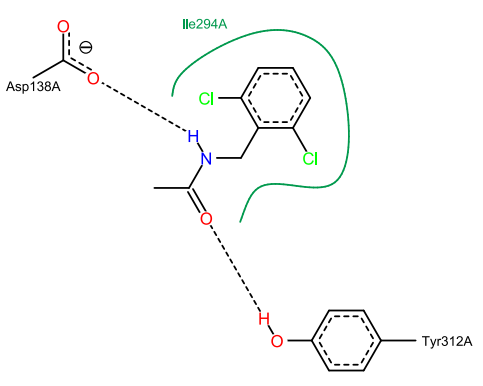

FMOMB76B / KOR

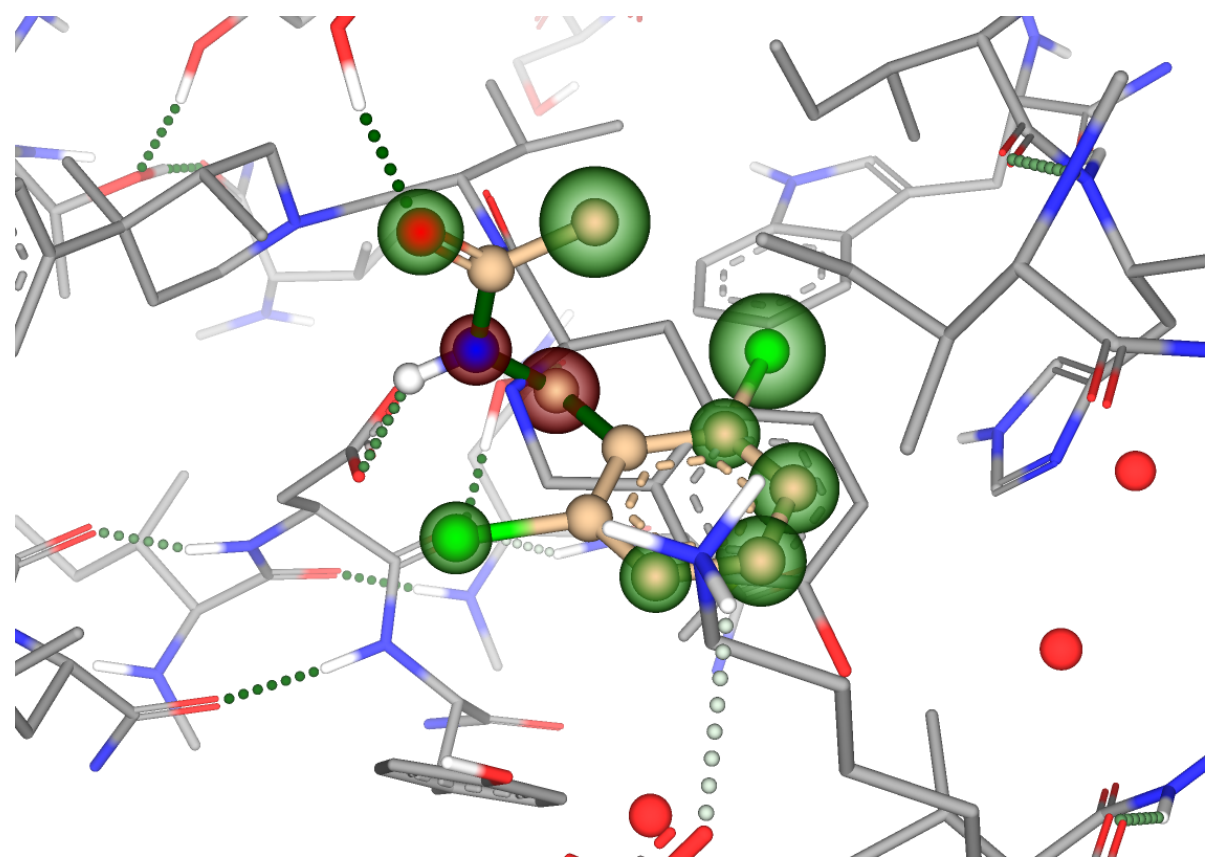

Figure 25: Three-dimensional docking view of FMOMB76b against KOR over JDTic as reference in SeeSAR 
bioRxiv preprint doi: https://doi.org/10.1101/432468; this version posted October 3, 2018. The copyright holder for this preprint (which was not certified by peer review) is the author/funder. All rights reserved. No reuse allowed without permission.

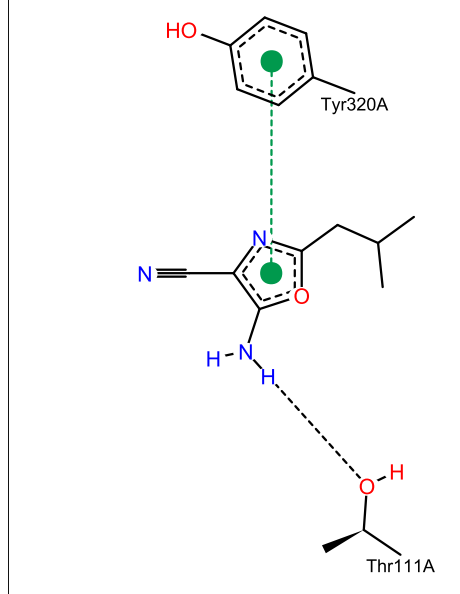

FMOSA1515 / KOR

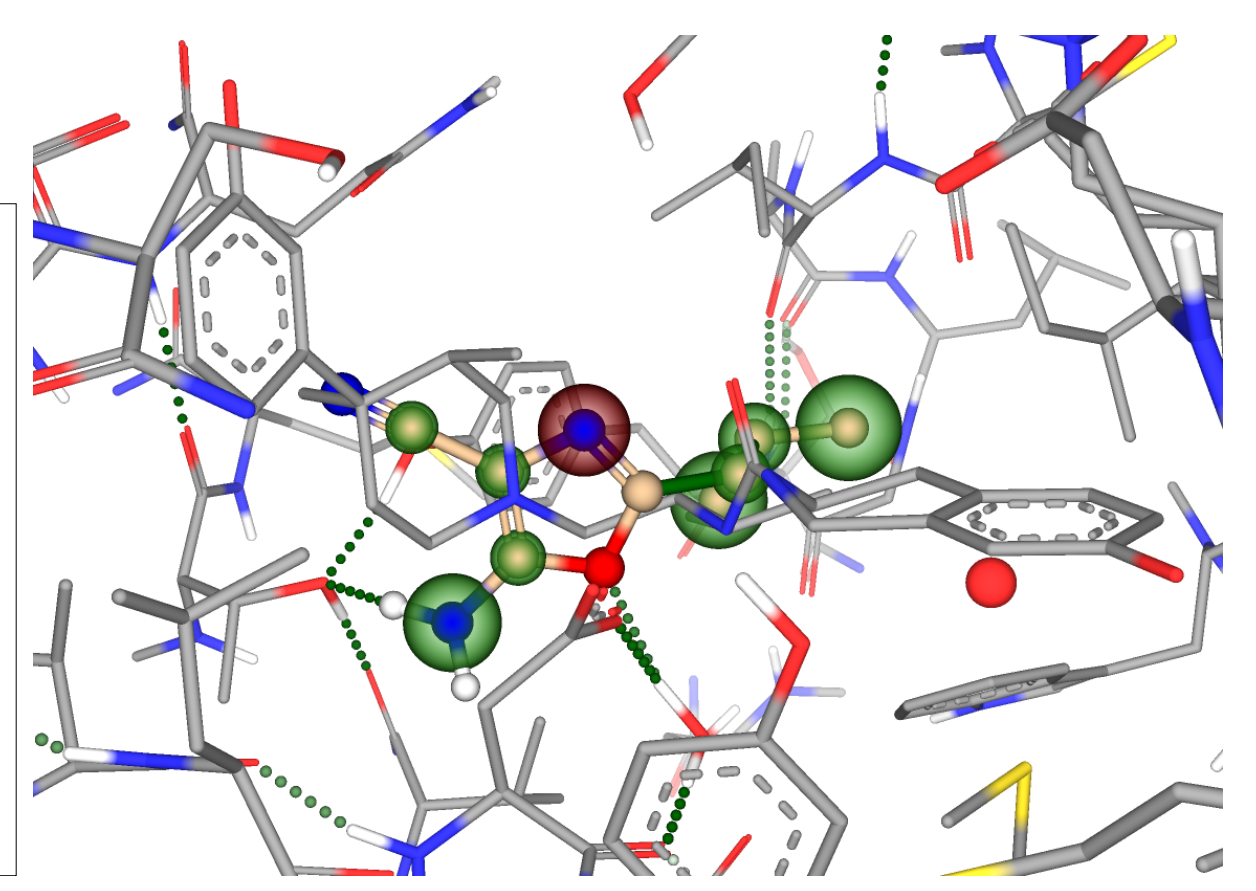

Figure 26: Three-dimensional docking view of FMOSA1515 against KOR over JDTic as reference in SeeSAR

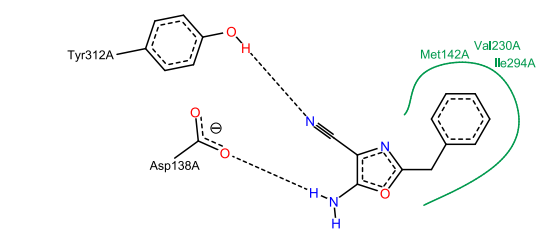

FMOSA1544 / KOR

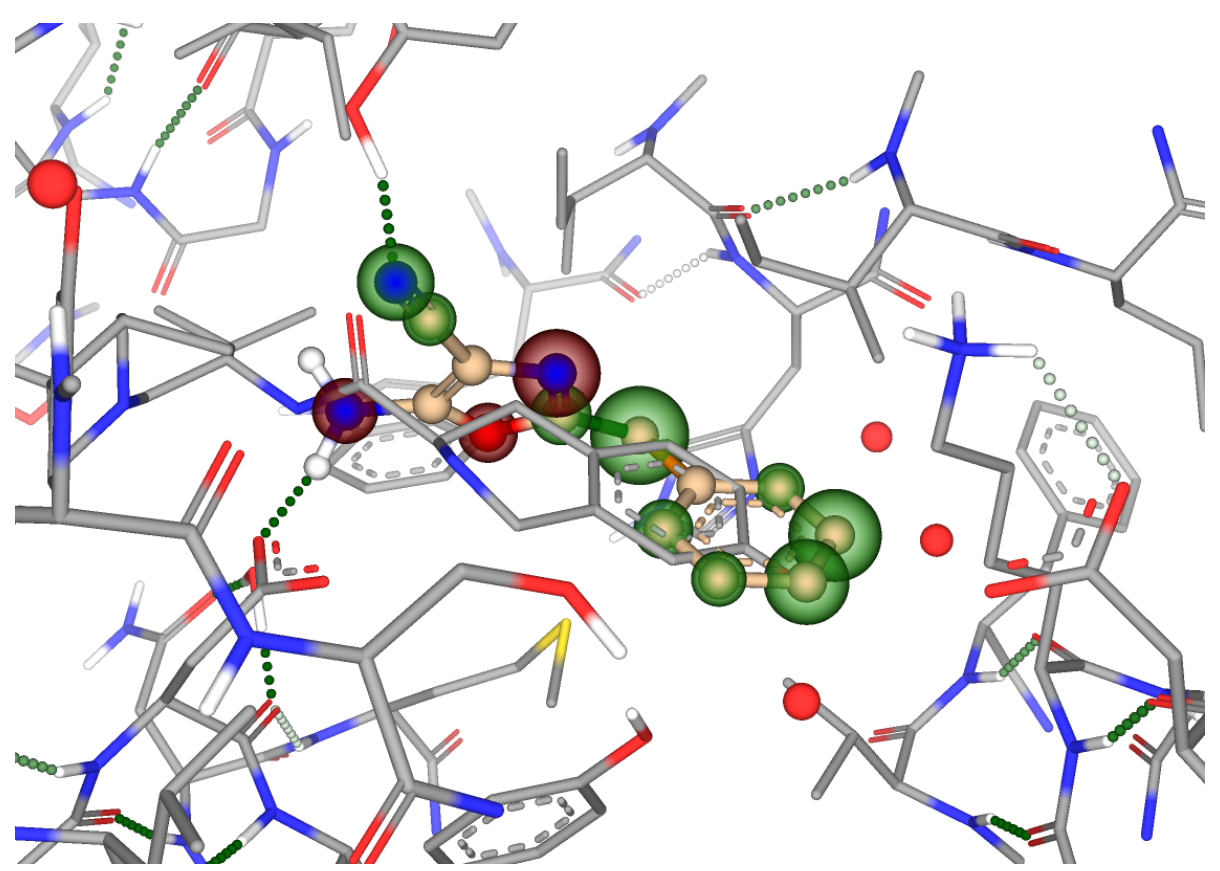

Figure 27: Three-dimensional docking view of FMOSA1544 against KOR over JDTic as reference in SeeSAR 
These results are indeed very interesting, overlapping the original antagonist JDTic - in every single case, the estimated average binding affinity's lower bound is much lower than the experimental values for PHIP(2). One should however note, that FMOSA1515 is predicted to not have any H-bonds towards KOR, and that an average between lower- and upper bound results in better binding towards $\operatorname{PHIP}(2)$ than KOR. Looking the average estimated binding affinity for each ligand, they are still much greater towards KOR in comparison to PHIP(2), except in the case of FMOSA1515 and FMOSA1544. The result for FMOSA1515 is however unreliable, since no H-bonds are predicted. ASP138A is the most occurring binding residue, followed by ILE294. In the case of XTS942, both nitrogens are predicted to form H-bonds towards ASP138A.

\section{Conclusion and future plans}

Having found at least 2 new distinct pharmacophores with high estimated binding affinity towards PHIP(2) and with the exception of EP300, are weak binders at other bromodomains, which are strong binders at KOR/MOR, there could be a structure-activity relationship between two targets, in a similar way to how PHIP interacts with IRS1. In the future, we would like to test protein-protein interaction between bromodomains and opioid receptors, as well as conduct binding studies and X-ray crystallography on the found ligands in combination with PHIP(2). Moreover, a relationship between PHIP(2)/EP300 and KOR antagonists could also mean that functionally selective ligands for other receptors are potentially targetting other bromodomains, opening the door for much more functionally selective GPCR drug design, reducing both chances of unwanted side-effects as well as risk of great investment loss by late stage clinical trials failures.

\section{Methods}

SeeSAR 8.0 and PoseView were downloaded from the BioSolveIT GmbH website (https://www.biosolveit.de/download/). The project was initialised by downloading the 5ENB PDB using the SeeSAR interface and mol files were created by copying the SMILES strings from the bindingDB website (https://www.bindingdb.org) and pasting them into MarvinSketch. These were imported into SeeSAR and every molecule was docked as follows:

1) Generate poses

2) Calculate estimated affinity

3) Removal off all but the highest affinity pose

4) Repeat steps 1 through 3 until the suffix of the highest binding ligand is shorter than that of all of the other poses for the same ligand

Once this was done for all molecules, each ligand was exported individually and PoseView was used with the following command:

poseview.exe $-1<$ ligand $>$.sdf - p 5enb.pdb - o $<$ ligand $>$.svg $-\mathrm{t}<$ ligand $>$

\section{Acknowledgements}

The author thanks BioSolveIT GmbH (especially Dr Marcus Gastreich), Dr Evet Ghobrial, Dr Diana Jordan, and Dr Qiao Chen for their support throughout the years.

\section{References}

[1] Claudia Friesen, Mareike Roscher, Inis Hormann, Iduna Fichtner, Andreas Alt, Ralf A. Hilger, Klaus-Michael Debatin, and Erich Miltner. Cell death sensitization of leukemia cells by opioid receptor activation. Oncotarget, 4(5):677-690, May 2013. 
[2] Claudia Friesen, Mareike Roscher, Andreas Alt, and Erich Miltner. Methadone, commonly used as maintenance medication for outpatient treatment of opioid dependence, kills leukemia cells and overcomes chemoresistance. Cancer Research, 68(15):6059-6064, August 2008.

[3] Claudia Friesen, Inis Hormann, Mareike Roscher, Iduna Fichtner, Andreas Alt, Ralf Hilger, Klaus-Michael Debatin, and Erich Miltner. Opioid receptor activation triggering downregulation of cAMP improves effectiveness of anti-cancer drugs in treatment of glioblastoma. Cell Cycle, 13(10):1560-1570, May 2014.

[4] Zanxian Xia, Mingquan Guo, Han Liu, Luwei Jiang, Qiaoxia Li, Jian Peng, Jia-Da Li, Baoen Shan, Pinghui Feng, and Hong Ma. CBP-dependent Wnt/-catenin signaling is crucial in regulation of MDR1 transcription. Current Cancer Drug Targets, 15(6):519-532, 2015.

[5] R. Bouër, L. Barthe, C. Philibert, C. Tournaire, J. Woodley, and G. Houin. The roles of P-glycoprotein and intracellular metabolism in the intestinal absorption of methadone: in vitro studies using the rat everted intestinal sac. Fundamental \& Clinical Pharmacology, 13(4):494-500, 1999.

[6] R. Callaghan and J. R. Riordan. Synthetic and natural opiates interact with P-glycoprotein in multidrug-resistant cells. The Journal of Biological Chemistry, 268(21):16059-16064, July 1993.

[7] Séverine Crettol, Patricia Digon, Kerry Powell Golay, Marlyse Brawand, and Chin B. Eap. In vitro P-glycoproteinmediated transport of (R)-, (S)-, (R,S)-methadone, LAAM and their main metabolites. Pharmacology, 80(4):304-311, 2007.

[8] Susan L. Mercer and Andrew Coop. Opioid Analgesics and P-glycoprotein Efflux Transporters: A Potential SystemsLevel Contribution to Analgesic Tolerance. Current Topics in Medicinal Chemistry, 11(9):1157-1164, 2011.

[9] Monica Rodriguez, Ignacio Ortega, Itziar Soengas, Elena Suarez, John C. Lukas, and Rosario Calvo. Effect of Pglycoprotein inhibition on methadone analgesia and brain distribution in the rat. Journal of Pharmacy and Pharmacology, 56(3):367-374, March 2004.

[10] Jeffrey Fudin, Dania Vanesta Fontenelle, Hannah Rebecca Fudin, Cynthia Carlyn, Debra Ann Hinden, and Christopher C. Ashley. Potential P-glycoprotein Pharmacokinetic Interaction of Telaprevir With Morphine or Methadone. Journal of Pain $\&$ Palliative Care Pharmacotherapy, 27(3):261-267, August 2013.

[11] M. E. Goldsmith, J. M. Gudas, E. Schneider, and K. H. Cowan. Wild type p53 stimulates expression from the human multidrug resistance promoter in a p53-negative cell line. The Journal of Biological Chemistry, 270(4):1894-1898, January 1995.

[12] R. C. Bargou, K. Jürchott, C. Wagener, S. Bergmann, S. Metzner, K. Bommert, M. Y. Mapara, K. J. Winzer, M. Dietel, B. Dörken, and H. D. Royer. Nuclear localization and increased levels of transcription factor YB-1 in primary human breast cancers are associated with intrinsic MDR1 gene expression. Nature Medicine, 3(4):447-450, April 1997.

[13] G. Zhou and M. T. Kuo. NF-kappaB-mediated induction of mdr1b expression by insulin in rat hepatoma cells. The Journal of Biological Chemistry, 272(24):15174-15183, June 1997.

[14] Panagis Filippakopoulos, Sarah Picaud, Maria Mangos, Tracy Keates, Jean-Philippe Lambert, Dalia Barsyte-Lovejoy, Ildiko Felletar, Rudolf Volkmer, Susanne Müller, Tony Pawson, Anne-Claude Gingras, Cheryl H. Arrowsmith, and Stefan Knapp. Histone recognition and large-scale structural analysis of the human bromodomain family. Cell, 149(1):214-231, March 2012. 
[15] Michael Brand, Angelina R. Measures, Angelina M. Measures, Brian G. Wilson, Wilian A. Cortopassi, Rikki Alexander, Matthias Höss, David S. Hewings, Timothy P. C. Rooney, Robert S. Paton, and Stuart J. Conway. Small molecule inhibitors of bromodomain-acetyl-lysine interactions. ACS chemical biology, 10(1):22-39, January 2015.

[16] Edwige Nicodeme, Kate L. Jeffrey, Uwe Schaefer, Soren Beinke, Scott Dewell, Chun-Wa Chung, Rohit Chandwani, Ivan Marazzi, Paul Wilson, Hervé Coste, Julia White, Jorge Kirilovsky, Charles M. Rice, Jose M. Lora, Rab K. Prinjha, Kevin Lee, and Alexander Tarakhovsky. Suppression of inflammation by a synthetic histone mimic. Nature, 468(7327):11191123, December 2010.

[17] Panagis Filippakopoulos, Jun Qi, Sarah Picaud, Yao Shen, William B. Smith, Oleg Fedorov, Elizabeth M. Morse, Tracey Keates, Tyler T. Hickman, Ildiko Felletar, Martin Philpott, Shonagh Munro, Michael R. McKeown, Yuchuan Wang, Amanda L. Christie, Nathan West, Michael J. Cameron, Brian Schwartz, Tom D. Heightman, Nicholas La Thangue, Christopher A. French, Olaf Wiest, Andrew L. Kung, Stefan Knapp, and James E. Bradner. Selective inhibition of BET bromodomains. Nature, 468(7327):1067-1073, December 2010.

[18] Xavier Lucas, Daniel Wohlwend, Martin Hügle, Karin Schmidtkunz, Stefan Gerhardt, Roland Schüle, Manfred Jung, Oliver Einsle, and Stefan Günther. 4-Acyl pyrroles: mimicking acetylated lysines in histone code reading. Angewandte Chemie (International Ed. in English), 52(52):14055-14059, December 2013.

[19] Paul V. Fish, Panagis Filippakopoulos, Gerwyn Bish, Paul E. Brennan, Mark E. Bunnage, Andrew S. Cook, Oleg Federov, Brian S. Gerstenberger, Hannah Jones, Stefan Knapp, Brian Marsden, Karl Nocka, Dafydd R. Owen, Martin Philpott, Sarah Picaud, Michael J. Primiano, Michael J. Ralph, Nunzio Sciammetta, and John D. Trzupek. Identification of a Chemical Probe for Bromo and Extra C-Terminal Bromodomain Inhibition through Optimization of a FragmentDerived Hit. Journal of Medicinal Chemistry, 55(22):9831-9837, November 2012.

[20] David S. Hewings, Oleg Fedorov, Panagis Filippakopoulos, Sarah Martin, Sarah Picaud, Anthony Tumber, Christopher Wells, Monica M. Olcina, Katherine Freeman, Andrew Gill, Alison J. Ritchie, David W. Sheppard, Angela J. Russell, Ester M. Hammond, Stefan Knapp, Paul E. Brennan, and Stuart J. Conway. Optimization of 3,5-Dimethylisoxazole Derivatives as Potent Bromodomain Ligands. Journal of Medicinal Chemistry, 56(8):3217-3227, April 2013.

[21] Romain Gosmini, Van Loc Nguyen, Jérôme Toum, Christophe Simon, Jean-Marie G. Brusq, Gael Krysa, Olivier Mirguet, Alizon M. Riou-Eymard, Eric V. Boursier, Lionel Trottet, Paul Bamborough, Hugh Clark, Chun-wa Chung, Leanne Cutler, Emmanuel H. Demont, Rejbinder Kaur, Antonia J. Lewis, Mark B. Schilling, Peter E. Soden, Simon Taylor, Ann L. Walker, Matthew D. Walker, Rab K. Prinjha, and Edwige Nicodème. The Discovery of I-BET726 (GSK1324726a), a Potent Tetrahydroquinoline ApoA1 Up-Regulator and Selective BET Bromodomain Inhibitor. Journal of Medicinal Chemistry, 57(19):8111-8131, October 2014.

[22] Maria Hägg and Stefan Wennström. Activation of hypoxia-induced transcription in normoxia. Experimental Cell Research, 306(1):180-191, May 2005.

[23] David De Semir, Mehdi Nosrati, Vladimir Bezrookove, Altaf A. Dar, Scot Federman, Geraldine Bienvenu, Suraj Venna, Javier Rangel, Joan Climent, Tanja M. Meyer Tamgüney, Suresh Thummala, Schuyler Tong, Stanley P. L. Leong, Chris Haqq, Paul Billings, James R. Miller, Richard W. Sagebiel, Robert Debs, and Mohammed Kashani-Sabet. Pleckstrin homology domain-interacting protein (PHIP) as a marker and mediator of melanoma metastasis. Proceedings of the National Academy of Sciences, 109(18):7067-7072, May 2012.

[24] Vladimir Bezrookove, David De Semir, Mehdi Nosrati, Schuyler Tong, Clayton Wu, Suresh Thummala, Altaf A. Dar, Stanley P. L. Leong, James E. Cleaver, Richard W. Sagebiel, James R. Miller, and Mohammed Kashani-Sabet. Prognostic Impact of PHIP Copy Number in Melanoma: Linkage to Ulceration. Journal of Investigative Dermatology, 134(3):783790, March 2014. 
[25] Xiang Jiao, Christos Aravidis, Rajeshwari Marikkannu, Johanna Rantala, Simone Picelli, Tatjana Adamovic, Tao Liu, Paula Maguire, Barbara Kremeyer, Liping Luo, Susanna von Holst, Vinaykumar Kontham, Jessada Thutkawkorapin, Sara Margolin, Quan Du, Johanna Lundin, Kyriaki Michailidou, Manjeet K. Bolla, Qin Wang, Joe Dennis, Michael Lush, Christine B. Ambrosone, Irene L. Andrulis, Hoda Anton-Culver, Natalia N. Antonenkova, Volker Arndt, Matthias W. Beckmann, Carl Blomqvist, William Blot, Bram Boeckx, Stig E. Bojesen, Bernardo Bonanni, Judith S. Brand, Hiltrud Brauch, Hermann Brenner, Annegien Broeks, Thomas Brüning, Barbara Burwinkel, Qiuyin Cai, Jenny Chang-Claude, Nbcs Collaborators, Fergus J. Couch, Angela Cox, Simon S. Cross, Sandra L. Deming-Halverson, Peter Devilee, Isabel dos Santos-Silva, Thilo Dörk, Mikael Eriksson, Peter A. Fasching, Jonine Figueroa, Dieter Flesch-Janys, Henrik Flyger, Marike Gabrielson, Montserrat García-Closas, Graham G. Giles, Anna González-Neira, Pascal Guénel, Qi Guo, Melanie Gündert, Christopher A. Haiman, Emily Hallberg, Ute Hamann, Patricia Harrington, Maartje J. Hooning, John L. Hopper, Guanmengqian Huang, Anna Jakubowska, Michael E. Jones, Michael J. Kerin, Veli-Matti Kosma, Vessela N. Kristensen, Diether Lambrechts, Loic Le Marchand, Jan Lubinski, Arto Mannermaa, John W. M. Martens, Alfons Meindl, Roger L. Milne, Anna Marie Mulligan, Susan L. Neuhausen, Heli Nevanlinna, Julian Peto, Katri Pylkas, Paolo Radice, Valerie Rhenius, Elinor J. Sawyer, Marjanka K. Schmidt, Rita K. Schmutzler, Caroline Seynaeve, Mitul Shah, Jacques Simard, Melissa C. Southey, Anthony J. Swerdlow, Therese Truong, Camilla Wendt, Robert Winqvist, Wei Zheng, kConFab/AOCS Investigators, Javier Benitez, Alison M. Dunning, Paul D. P. Pharoah, Douglas F. Easton, Kamila Czene, Per Hall, Annika Lindblom, Xiang Jiao, Christos Aravidis, Rajeshwari Marikkannu, Johanna Rantala, Simone Picelli, Tatjana Adamovic, Tao Liu, Paula Maguire, Barbara Kremeyer, Liping Luo, Susanna von Holst, Vinaykumar Kontham, Jessada Thutkawkorapin, Sara Margolin, Quan Du, Johanna Lundin, Kyriaki Michailidou, Manjeet K. Bolla, Qin Wang, Joe Dennis, Michael Lush, Christine B. Ambrosone, Irene L. Andrulis, Hoda Anton-Culver, Natalia N. Antonenkova, Volker Arndt, Matthias W. Beckmann, Carl Blomqvist, William Blot, Bram Boeckx, Stig E. Bojesen, Bernardo Bonanni, Judith S. Brand, Hiltrud Brauch, Hermann Brenner, Annegien Broeks, Thomas Brüning, Barbara Burwinkel, Qiuyin Cai, Jenny Chang-Claude, Nbcs Collaborators, Fergus J. Couch, Angela Cox, Simon S. Cross, Sandra L. Deming-Halverson, Peter Devilee, Isabel dos Santos-Silva, Thilo Dörk, Mikael Eriksson, Peter A. Fasching, Jonine Figueroa, Dieter Flesch-Janys, Henrik Flyger, Marike Gabrielson, Montserrat García-Closas, Graham G. Giles, Anna González-Neira, Pascal Guénel, Qi Guo, Melanie Gündert, Christopher A. Haiman, Emily Hallberg, Ute Hamann, Patricia Harrington, Maartje J. Hooning, John L. Hopper, Guanmengqian Huang, Anna Jakubowska, Michael E. Jones, Michael J. Kerin, Veli-Matti Kosma, Vessela N. Kristensen, Diether Lambrechts, Loic Le Marchand, Jan Lubinski, Arto Mannermaa, John W. M. Martens, Alfons Meindl, Roger L. Milne, Anna Marie Mulligan, Susan L. Neuhausen, Heli Nevanlinna, Julian Peto, Katri Pylkas, Paolo Radice, Valerie Rhenius, Elinor J. Sawyer, Marjanka K. Schmidt, Rita K. Schmutzler, Caroline Seynaeve, Mitul Shah, Jacques Simard, Melissa C. Southey, Anthony J. Swerdlow, Therese Truong, Camilla Wendt, Robert Winqvist, Wei Zheng, kConFab/AOCS Investigators, Javier Benitez, Alison M. Dunning, Paul D. P. Pharoah, Douglas F. Easton, Kamila Czene, Per Hall, and Annika Lindblom. PHIP - a novel candidate breast cancer susceptibility locus on 6q14.1. Oncotarget, 8(61):102769-102782, October 2017.

[26] Lei Wei, Brian L. Murphy, Gang Wu, Matthew Parker, John Easton, Richard J. Gilbertson, Jinghui Zhang, Martine F. Roussel, Lei Wei, Brian L. Murphy, Gang Wu, Matthew Parker, John Easton, Richard J. Gilbertson, Jinghui Zhang, and Martine F. Roussel. Exome sequencing analysis of murine medulloblastoma models identifies WDR11 as a potential tumor suppressor in Group 3 tumors. Oncotarget, 8(39):64685-64697, July 2017.

[27] Oakley B. Cox, Tobias Krojer, Patrick Collins, Octovia Monteiro, Romain Talon, Anthony Bradley, Oleg Fedorov, Jahangir Amin, Brian D. Marsden, John Spencer, Frank von Delft, and Paul E. Brennan. A poised fragment library enables rapid synthetic expansion yielding the first reported inhibitors of $\operatorname{PHIP}(2)$, an atypical bromodomain. Chemical Science, 7(3):2322-2330, March 2016.

[28] Oakley B. Cox, Tobias Krojer, Patrick Collins, Octovia Monteiro, Romain Talon, Anthony Bradley, Oleg Fedorov, Jahangir Amin, Brian D. Marsden, John Spencer, Frank von Delft, and Paul Brennan. Human Pleckstrin Homology domain Interacting Protein (PHIP); A Target Enabling Package, June 2016. type: dataset. 
[29] Ingo Reulecke, Gudrun Lange, Jürgen Albrecht, Robert Klein, and Matthias Rarey. Towards an Integrated Description of Hydrogen Bonding and Dehydration: Decreasing False Positives in Virtual Screening with the HYDE Scoring Function. ChemMedChem, 3(6):885-897, June 2008.

[30] Nadine Schneider, Gudrun Lange, Sally Hindle, Robert Klein, and Matthias Rarey. A consistent description of HYdrogen bond and DEhydration energies in protein-ligand complexes: methods behind the HYDE scoring function. Journal of Computer-Aided Molecular Design, 27(1):15-29, January 2013.

[31] Z. X. Wang, Y. C. Zhu, W. Q. Jin, X. J. Chen, J. Chen, R. Y. Ji, and Z. Q. Chi. Stereoisomers of N-[1-hydroxy(2-phenylethyl)-3-methyl-4-piperidyl]- N-phenylpropanamide: synthesis, stereochemistry, analgesic activity, and opioid receptor binding characteristics. Journal of Medicinal Chemistry, 38(18):3652-3659, September 1995.

[32] Xuemei Peng, Brian I. Knapp, Jean M. Bidlack, and John L. Neumeyer. Synthesis and preliminary in vitro investigation of bivalent ligands containing homo- and heterodimeric pharmacophores at mu, delta, and kappa opioid receptors. Journal of Medicinal Chemistry, 49(1):256-262, January 2006.

[33] John L. Neumeyer, Ao Zhang, Wennan Xiong, Xiao-Hui Gu, James E. Hilbert, Brian I. Knapp, S. Stevens Negus, Nancy K. Mello, and Jean M. Bidlack. Design and synthesis of novel dimeric morphinan ligands for kappa and micro opioid receptors. Journal of Medicinal Chemistry, 46(24):5162-5170, November 2003.

[34] Yulin Wang, Kang Tang, Saadet Inan, Daniel Siebert, Ulrike Holzgrabe, David Y. W. Lee, Peng Huang, Jian-Guo Li, Alan Cowan, and Lee-Yuan Liu-Chen. Comparison of pharmacological activities of three distinct kappa ligands (Salvinorin A, TRK-820 and $3 \mathrm{flb}$ ) on kappa opioid receptors in vitro and their antipruritic and antinociceptive activities in vivo. The Journal of Pharmacology and Experimental Therapeutics, 312(1):220-230, January 2005.

[35] J. B. Thomas, S. W. Mascarella, R. B. Rothman, J. S. Partilla, H. Xu, K. B. McCullough, C. M. Dersch, B. E. Cantrell, D. M. Zimmerman, and F. I. Carroll. Investigation of the N-substituent conformation governing potency and mu receptor subtype-selectivity in $(+)-(3 \mathrm{r}, 4 \mathrm{r})$-dimethyl-4-(3-hydroxyphenyl)piperidine opioid antagonists. Journal of Medicinal Chemistry, 41(11):1980-1990, May 1998.

[36] Ming-Qiang Zheng, Su Jin Kim, Daniel Holden, Shu-fei Lin, Anne Need, Karen Rash, Vanessa Barth, Charles Mitch, Antonio Navarro, Michael Kapinos, Kathleen Maloney, Jim Ropchan, Richard E. Carson, and Yiyun Huang. An Improved Antagonist Radiotracer for the Kappa Opioid Receptor: Synthesis and Characterization of 11c-LY2459989. Journal of nuclear medicine : official publication, Society of Nuclear Medicine, 55(7):1185-1191, July 2014.

[37] Nurulain T. Zaveri, V. Blair Journigan, and Willma E. Polgar. Discovery of the First Small-Molecule Opioid Pan Antagonist with Nanomolar Affinity at Mu, Delta, Kappa, and Nociceptin Opioid Receptors. ACS Chemical Neuroscience, 6(4):646-657, April 2015.

[38] Huixian Wu, Daniel Wacker, Mauro Mileni, Vsevolod Katritch, Gye Won Han, Eyal Vardy, Wei Liu, Aaron A. Thompson, Xi-Ping Huang, F. Ivy Carroll, S. Wayne Mascarella, Richard B. Westkaemper, Philip D. Mosier, Bryan L. Roth, Vadim Cherezov, and Raymond C. Stevens. Structure of the human -opioid receptor in complex with JDTic. Nature, 485(7398):327-332, May 2012. 